Supporting information for the article

\title{
On-Water Selectivity Switch in Microdroplets in the 1,2,3-Triazole Synthesis from Bromoethenesulfonyl Fluoride
}

\author{
Dmitry B. Eremin and Valery V. Fokin*
}

The Bridge@USC, University of Southern California, 1002 Childs Way, Los Angeles, CA 90089-3502, United States *E-mail: fokin@usc.edu

\section{CONTENTS}

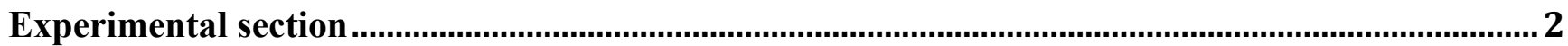

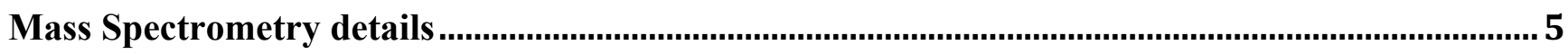

Computational data

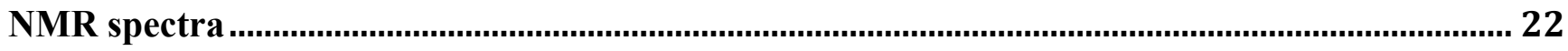

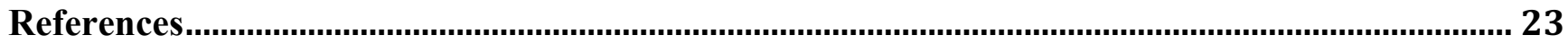




\section{Experimental section}

General considerations. MeCN (LC/MS grade), DMF (HPLC grade), PhMe (HPLC grade), DCM (HPLC grade), water (LC/MS grade), and Formic acid (LC/MS grade) for ESI-MS experiments were ordered from Fisher Scientific and used as received. Commercial chemicals were obtained from: $\mathrm{D}_{2} \mathrm{O}$, $\mathrm{CDCl}_{3}$ (Cambridge Isotope Laboratories, Inc.), $\mathrm{HCl}$ (Merck), $\mathrm{KHF}_{2}$ (Acros Organics), DCM, EtOAC, Hexanes (Fisher Scientific) and were used as received. BnN 3 and BrESF were obtained by previously published procedures. ${ }^{[1]}$ Tunemix solution for calibration was ordered from Agilent Technologies. The samples for APCI-MS experiments were prepared in $1.8 \mathrm{~mL}$ glass vials/screw top caps with PTFE septa for HPLC experiments (Agilent Technologies). Aliquot sampling was conducted by using Hamilton syringes or RAININ pipets. pH was measured using Apera PH700 pH Meter equipped with 201T-S electrode.

ESI-(+)MS experiments. Mass spectra were measured using an Agilent 6545XT qToF instrument coupled with 1290 LC system. The qToF mass spectrometer was equipped with a dual AJS electrospray ionization source. In positive ion mode ionization parameters are as follows: Capillary Voltage $-4.5 \mathrm{kV}$, Nozzle Voltage $-1.0 \mathrm{kV}$, nitrogen was applied as a nebulizer gas $(10,15,20,25$, or $35 \mathrm{psi})$, sheath gas $4 \mathrm{~L} \times \min ^{-1}, 180{ }^{\circ} \mathrm{C}$, dry gas $4 \mathrm{~L} \times \min ^{-1}, 200{ }^{\circ} \mathrm{C}$, and collision gas. Spectra were recorded in $m / z 100-$ 1700 range. For external calibration and tuning a low-concentration tuning mix solution by Agilent Technologies was utilized at 10:1 further dilution. Samples were injected through the main nebulizer using a syringe pump, fitted with a $500 \mu \mathrm{L}$ Hamilton syringe $(1750 \mathrm{RN})$ at 2 or $5 \mu \mathrm{L} \times \mathrm{min}^{-1}$ flow rate. Water (or corresponding solutions) was introduced through the reference nebulizer via LC pump (1290) at varied flow rates $\left(0-500 \mu \mathrm{L} \times \mathrm{min}^{-1}\right)$. See Figure $\mathrm{S} 1$ for ion source setup. All MS spectra were recorded at $1 \mathrm{~Hz}$. Spectra were processed using Agilent MassHunter 10.0 software package.

NMR Experiments. All NMR measurements were performed using a three-channel Varian VNMRS600 spectrometer, operating at 600.1 and $150.0 \mathrm{MHz}$ for ${ }^{1} \mathrm{H}$ and ${ }^{13} \mathrm{C}$, respectively. Samples for NMR experiments were prepared in $\mathrm{CDCl}_{3}$. The ${ }^{1} \mathrm{H}$ chemical shifts are reported relative to the residual protic solvent peak $\left(\mathrm{CHCl}_{3} 7.26 \mathrm{ppm}\right)$. The ${ }^{13} \mathrm{C}$ chemical shifts are reported relative to the corresponding solvent signals $\left(\mathrm{CDCl}_{3} 77.16 \mathrm{ppm}\right)$. The spectra were processed on a macOS workstation using the TOPSPIN 4.0 software package.

GC-qToF-MS measurements. The GC-MS measurements were performed with an Agilent 7890 GC system equipped with an Agilent 7250 qToF mass detector (electron ionization, $70 \mathrm{eV}$ and $15 \mathrm{eV}$ for low-EV mode to obtain molecular ion) and an HP-5MS column $(30 \mathrm{~m} \times 0.25 \mathrm{~mm} \times 0.25 \mu \mathrm{m}$ film $)$ using $\mathrm{He}$ as a carrier gas at a flow of $1.0 \mathrm{~mL} \times \mathrm{min}^{-1}$. The following temperature program was used in the GCMS measurements: initial temperature: $60{ }^{\circ} \mathrm{C}$, hold for $2 \mathrm{~min}$, then $20^{\circ} \mathrm{C} \times \min ^{-1}$ to $300{ }^{\circ} \mathrm{C}$ and hold for 
3 min. Nitrogen was used as a collision gas. All the MS spectra were recorded at $1 \mathrm{~Hz}$. Spectra were processed using Agilent MassHunter 10.0 software package.

GC-Q-MS/FID measurements. The GC-MS measurements were performed with an Agilent 9000 Intuvo GC system equipped with an Agilent 5977B Q mass detector (electron ionization, $70 \mathrm{eV}$ ) and flame-ionization detector (FID); and an HP-5MS column (30 $\mathrm{m} \times 0.25 \mathrm{~mm} \times 0.25 \mu \mathrm{m}$ film) using He as a carrier gas at a flow of $1.0 \mathrm{~mL} \times \mathrm{min}^{-1}$. The following temperature program was used in the GC-MS measurements: initial temperature: $60{ }^{\circ} \mathrm{C}$, hold for $1 \mathrm{~min}$, then $20^{\circ} \mathrm{C} \times \mathrm{min}^{-1}$ to $300{ }^{\circ} \mathrm{C}$ and hold for 2 min. After column flow is split 1:1 for simultaneous MS and FID detection. All the MS spectra were recorded at $1 \mathrm{~Hz}$. Spectra were processed using Agilent MassHunter 10.0 software package.

Computational details. Molecular structures of reagents, intermediates, transition states and products were optimized at the PBE0-D3/def2-TZVP level with SMD solvent model for water. For PBE0 ${ }^{[2]}$ method empirical Grimme's D3 dispersion corrections ${ }^{[3]}$ were used for more accurate description of the dispersion interaction, def2-TZVP basis set was used for all atoms. ${ }^{[4]}$ For all structures, the vibrational spectrum was calculated to determine the type of a stationary point of the potential energy surface. Optimized molecular structures of reagents, intermediates and products correspond to minima of potential energy surface.

PES calculation was carried out by Q-Chem 5.3 software package; ${ }^{[5]}$ geometry guess for transition states were found by using single ended growing string method by pyGSM ${ }^{[6]}$ package with Q-Chem 5.3 engine; for visualization of molecular structures CYLview ${ }^{[7]}$ and iQmol ${ }^{[8]}$ software was used; PES was plotted using a developed Python script based on cclib $^{[9]}$ and pyEnergyDiagrams. ${ }^{[10]}$

\section{Synthesis of 1-benzyl-4-bromo-1,2,3-triazole (3).}

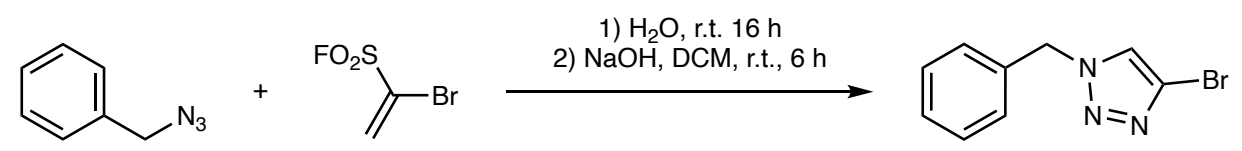

A screw-top vial $(20 \mathrm{ml})$ was charged with $266 \mathrm{mg}(2 \mathrm{mmol})$ of benzyl azide and $4 \mathrm{~mL}$ of water, equipped with a magnetic stirring bar and placed on a stirring plate. At 1,400 rpm agitation, $756 \mathrm{mg}$ (4 mmol) of 1-bromo-1-ethylenesulfonyl fluoride were added at once. The vial was closed and left stirring for $16 \mathrm{~h}$ at r.t. After $16 \mathrm{~h}$ conversion was examined by GC-MS. (NOTE: A 3:1 ratio of products was obtained upon analysis of 3:4 ratio. Although the general "on-water" conditions do not provide same selectivity, we attribute this effect to inefficiency of the emulsion formation. The water surface in the spray plume is larger, which prevents the reaction to occur in the organic phase and produce the undesired product.)

At next step $4 \mathrm{~mL}$ of DCM and $4 \mathrm{~mL}$ of $2 \mathrm{M} \mathrm{NaOH}$ were added, and reaction mixture was left for 6 hours stirring at r.t. Completeness of hydrolysis was confirmed by GC-MS. The mixture was transferred into the separatory funnel, and $20 \mathrm{~mL}$ of water was added. The organic layer was separated, and the 
remaining product was extracted with DCM $(3 \times 10 \mathrm{~mL})$. The combined organic layer was washed with water $(2 \times 15 \mathrm{~mL}), \mathrm{pH}$ was checked to be neutral in water wash, then the organic fractions were washed with brine $(2 \times 15 \mathrm{~mL})$. The mixture was dried over $\mathrm{Na}_{2} \mathrm{SO}_{4}$, and DCM was removed in vacuo. Column chromatography on silica gel (40:1 silica gel: product) with EtOAc: hexanes $1: 2$ afford white crystalline product 3 . Yield $265 \mathrm{mg} ; 56 \%$.

${ }^{1} \mathrm{H} \mathrm{NMR}\left(\mathrm{CDCl}_{3} ; \delta, \mathrm{ppm}\right): 7.45(1 \mathrm{H}, \mathrm{s}), 7.42-7.36(3 \mathrm{H}, \mathrm{m}), 7.31-7.27(2 \mathrm{H}, \mathrm{m}), 5.53(2 \mathrm{H}, \mathrm{s})$.

${ }^{13} \mathrm{C}\left\{{ }^{1} \mathrm{H}\right\} \mathrm{NMR}\left(\mathrm{CDCl}_{3} ; \delta, \mathrm{ppm}\right): 133.9,129.4,129.3,128.3,123.7,121.0,55.0$.

EI-MS (TOF): calcd for $\mathrm{C}_{9} \mathrm{H}_{8} \mathrm{BrN}_{3}[\mathrm{M}]^{+\bullet} \mathrm{m} / z$ 236.9897, found $m / z 236.9897$ ( $\Delta=0.0 \mathrm{ppm}$ ).

Collection and analysis of the spray content. Two nebulizers were fixed on a stand (Figure S1) and aligned. Nebulizers were introduced into a $1 \mathrm{~L}$ beaker; glass wool was placed onto the bottom of the beaker. A solution (same as for in-source experiments: $1 \mathrm{mM} \mathrm{BnN}_{3}, 2 \mathrm{mM} \mathrm{BrESF}$ in $\mathrm{MeCN}$ ) was supplied through a vertical nebulizer at $10 \mu \mathrm{L} / \mathrm{min}$ flow rate for $100 \mathrm{~min}$, while water was sprayed through second nebulizer at $300 \mu \mathrm{L} / \mathrm{min}$. A pressure of $35 \mathrm{psi}$ was applied. The beaker was covered with lint-free cloth throughout collection. After $1 \mathrm{~mL}$ of the solution of reactants was used, organic content was extracted with $3 \times 10 \mathrm{~mL}$ of DCM. DCM was then removed under reduced pressure to $c a$. $0.5 \mathrm{~mL}$ volume. The sample was directly analyzed by GC-MS.

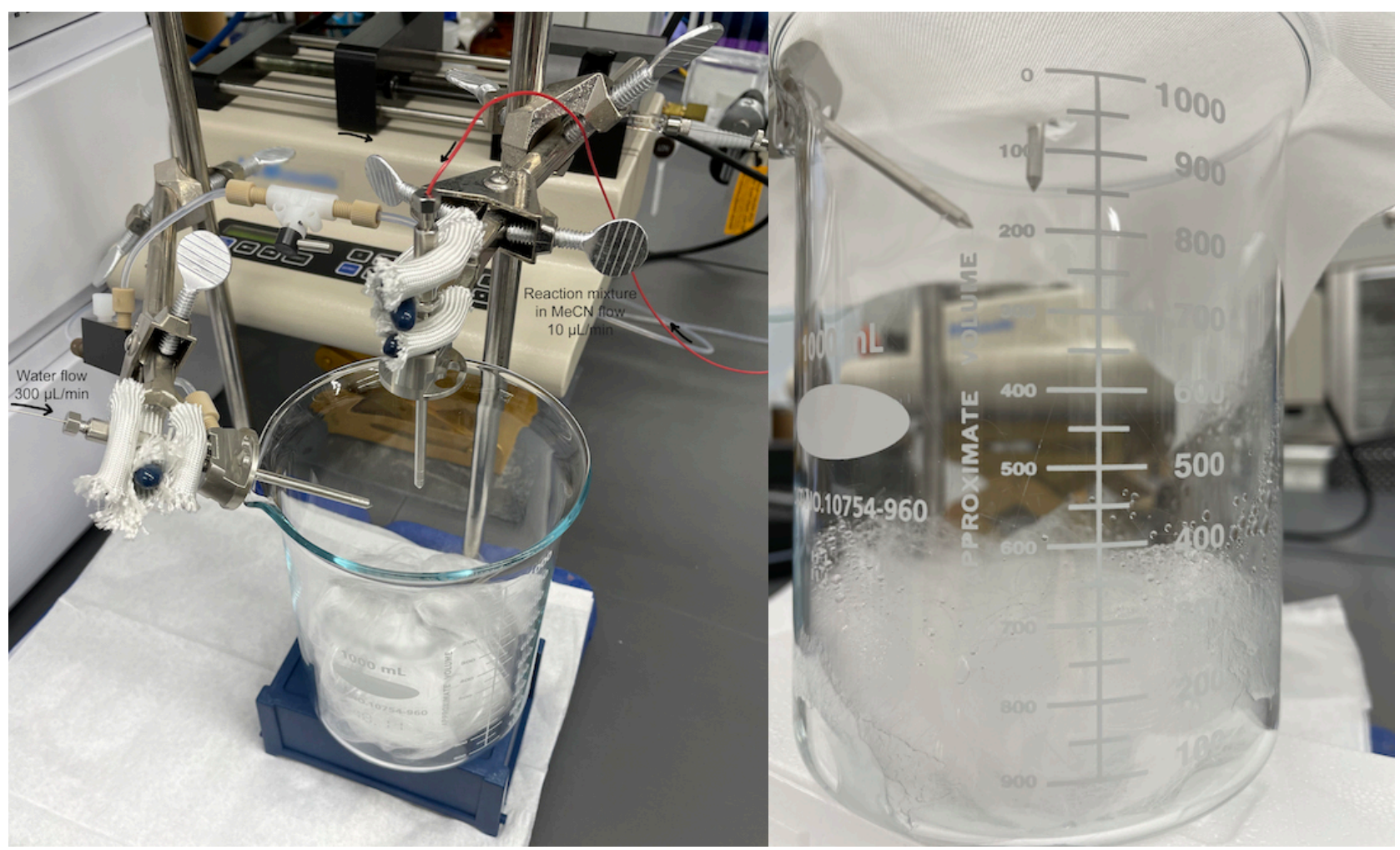

Figure S1. Photo of a dual spray setup used for on-microdroplet reactions. 


\section{Mass Spectrometry details}

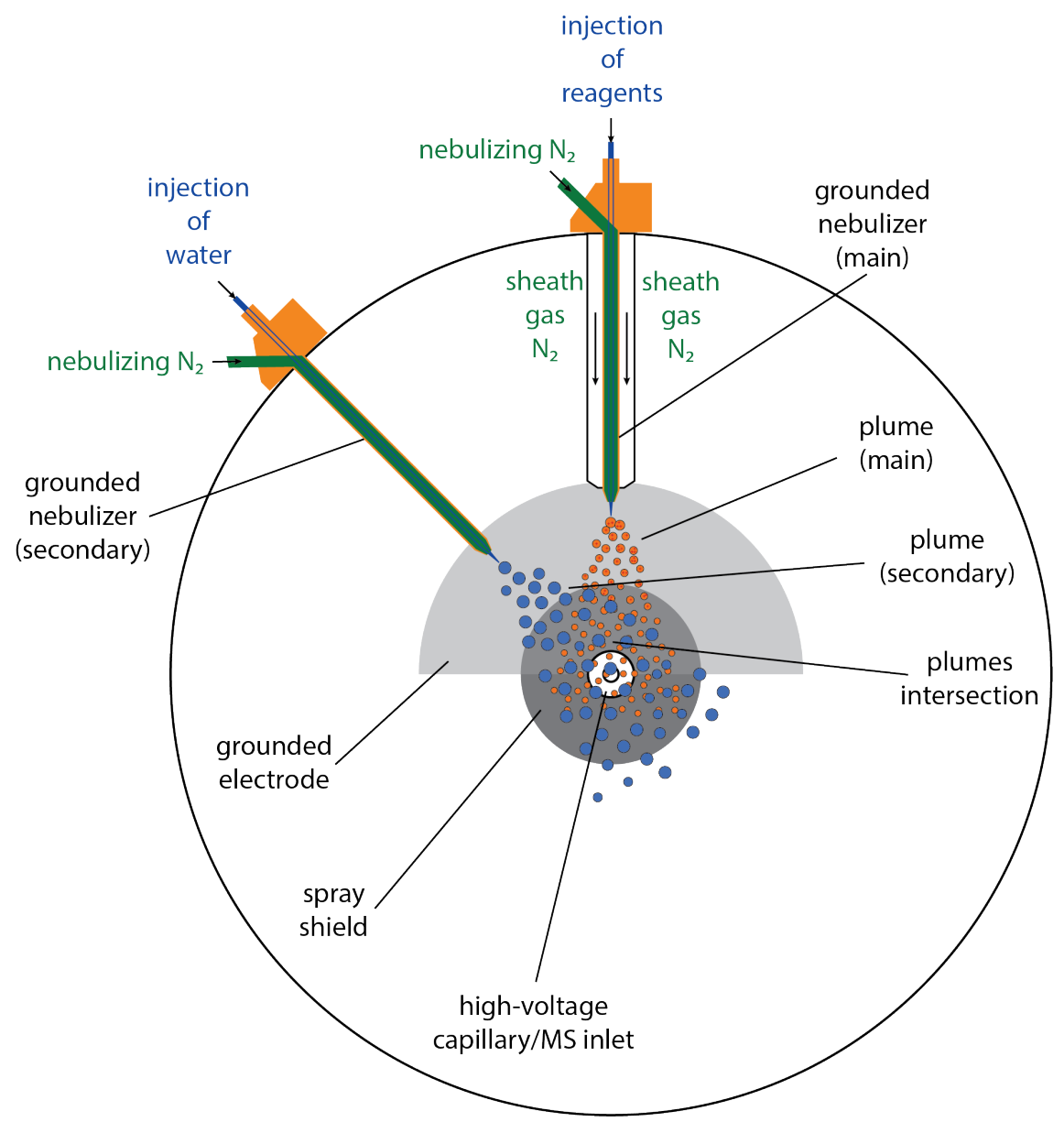

Figure S2. Scheme of a dual AJS ionization source used for on-microdroplet reactions.

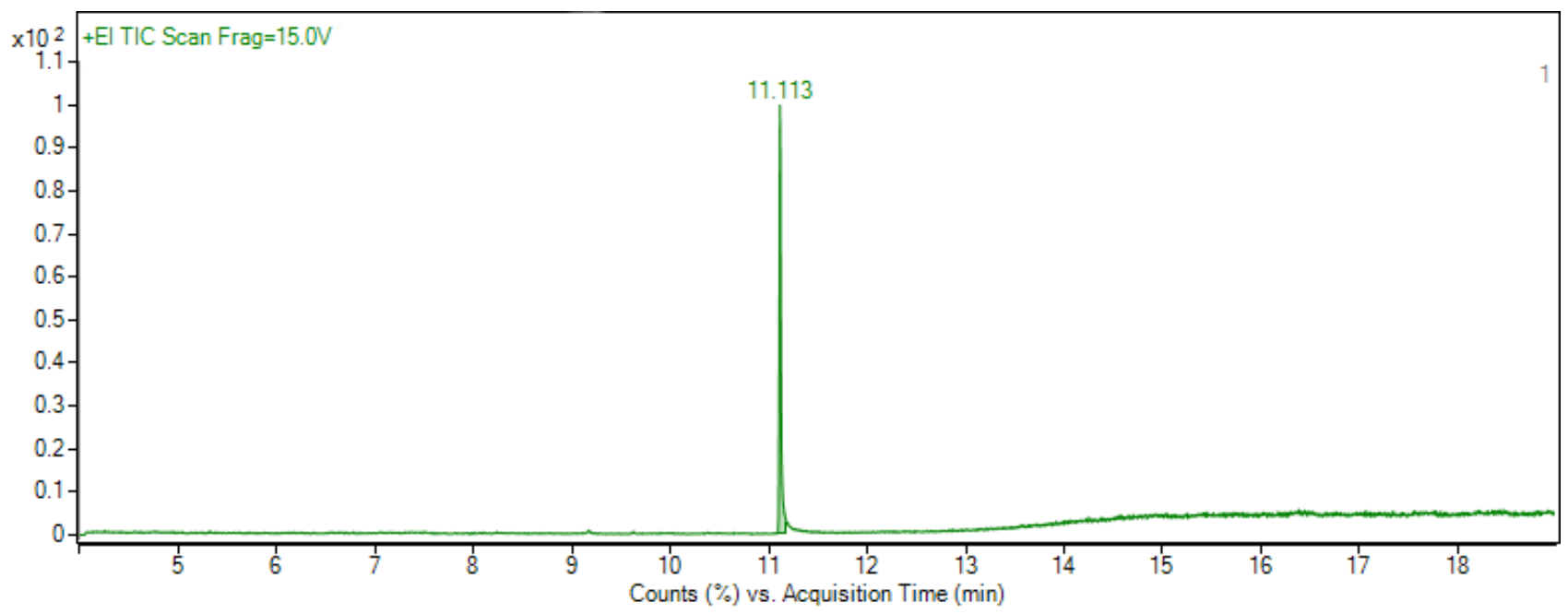

Figure S3. GC-EI-TOF-(+)MS total ion count chromatogram of purified 3. 


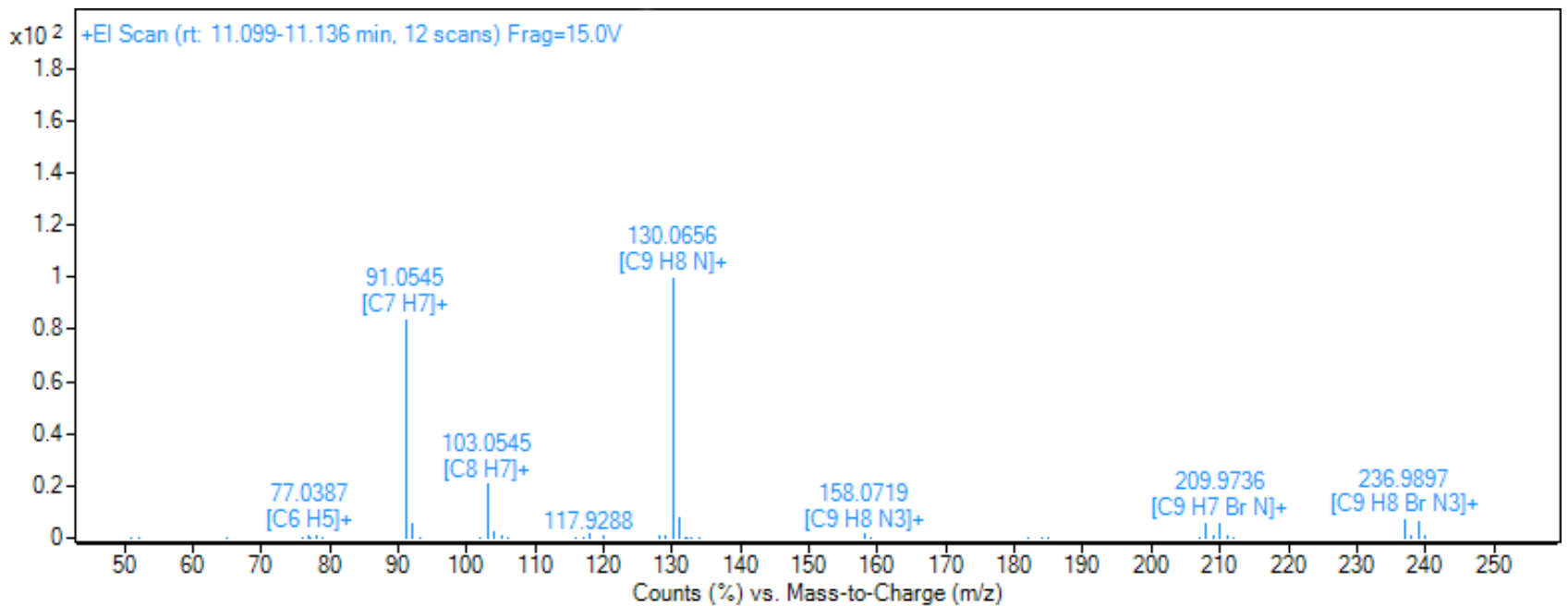

Figure S4. EI-TOF-(+)MS spectrum $(15 \mathrm{eV})$ of 3. Peak formulas generated at $5 \mathrm{ppm}$ error window.

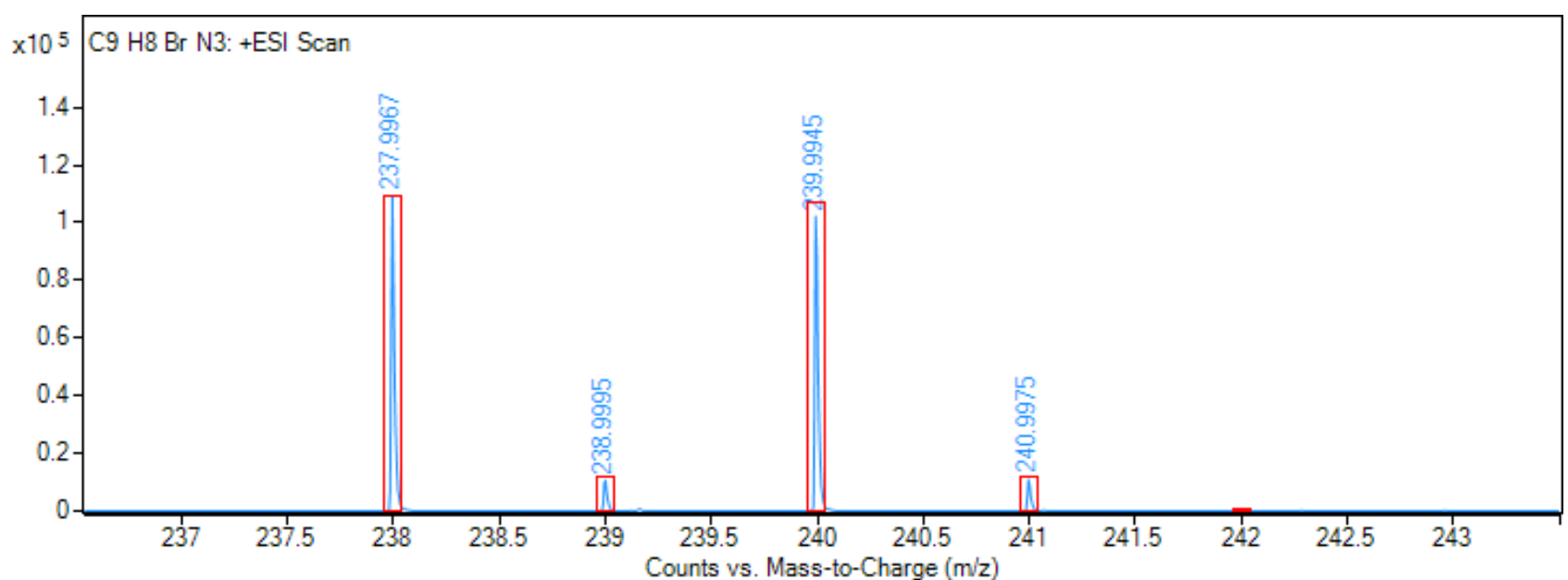

Figure S5. ESI-(+)MS spectrum of isolated 3 diluted in $\mathrm{CH}_{3} \mathrm{CN}$, expanded to the $[\mathbf{3}+\mathrm{H}]^{+}$region; red blocks denotes theoretical isotopic distribution corresponding to $\left[\mathrm{C}_{9} \mathrm{H}_{8} \mathrm{BrN}_{3}+\mathrm{H}\right]^{+}, \Delta=2.9 \mathrm{ppm}$.

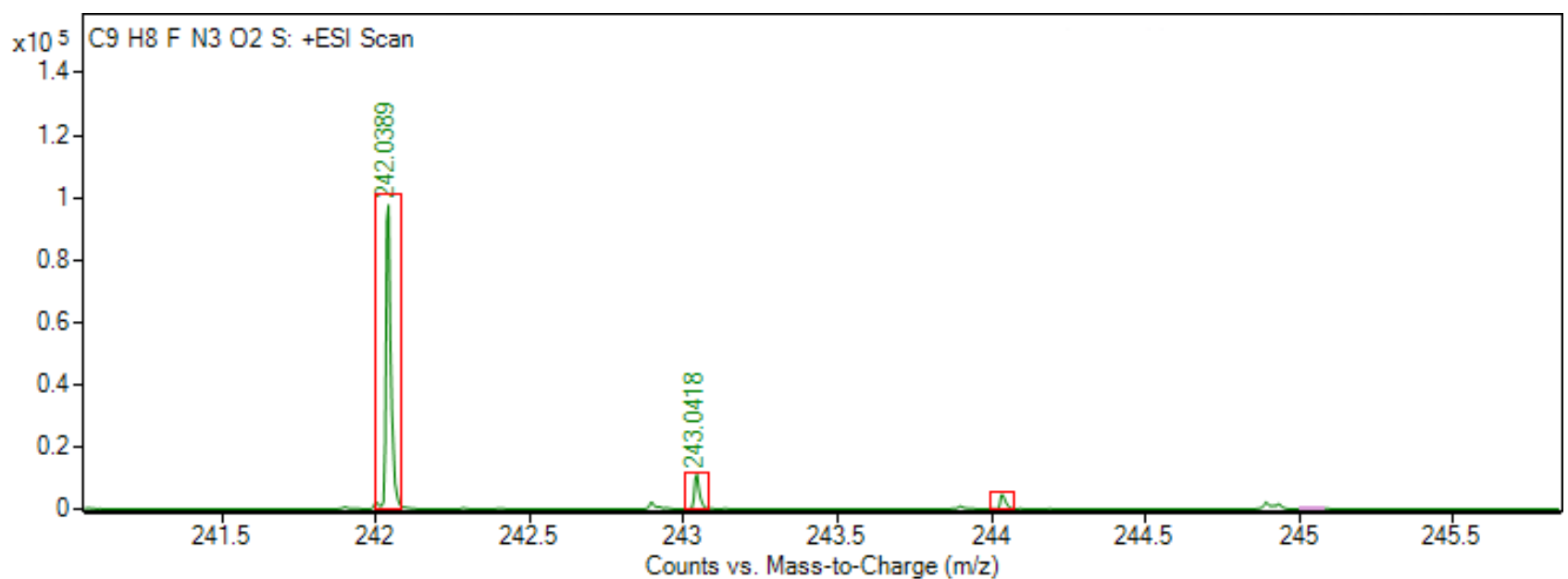

Figure S6. ESI-(+)MS spectrum of isolated 4 diluted in $\mathrm{CH}_{3} \mathrm{CN}$, expanded to the $[4+\mathrm{H}]^{+}$region; red blocks denotes theoretical isotopic distribution corresponding to $\left[\mathrm{C}_{9} \mathrm{H}_{8} \mathrm{FN}_{3} \mathrm{O}_{2} \mathrm{~S}+\mathrm{H}\right]^{+}, \Delta=2.1 \mathrm{ppm}$. 


\section{Comparison of ionization efficiency}

Direct injection of the solution of 3 and 4 (3:2 mixture) in $\mathrm{MeCN}(\sim 1 \mu \mathrm{g} / \mathrm{mL})$ resulted in quite low abundances of both products. Additionally, $\mathbf{3}$ is less abundant even though it dominates in the mixture. Thus, $\mathbf{3}$ has lower ionization efficiency comparing to 4 .

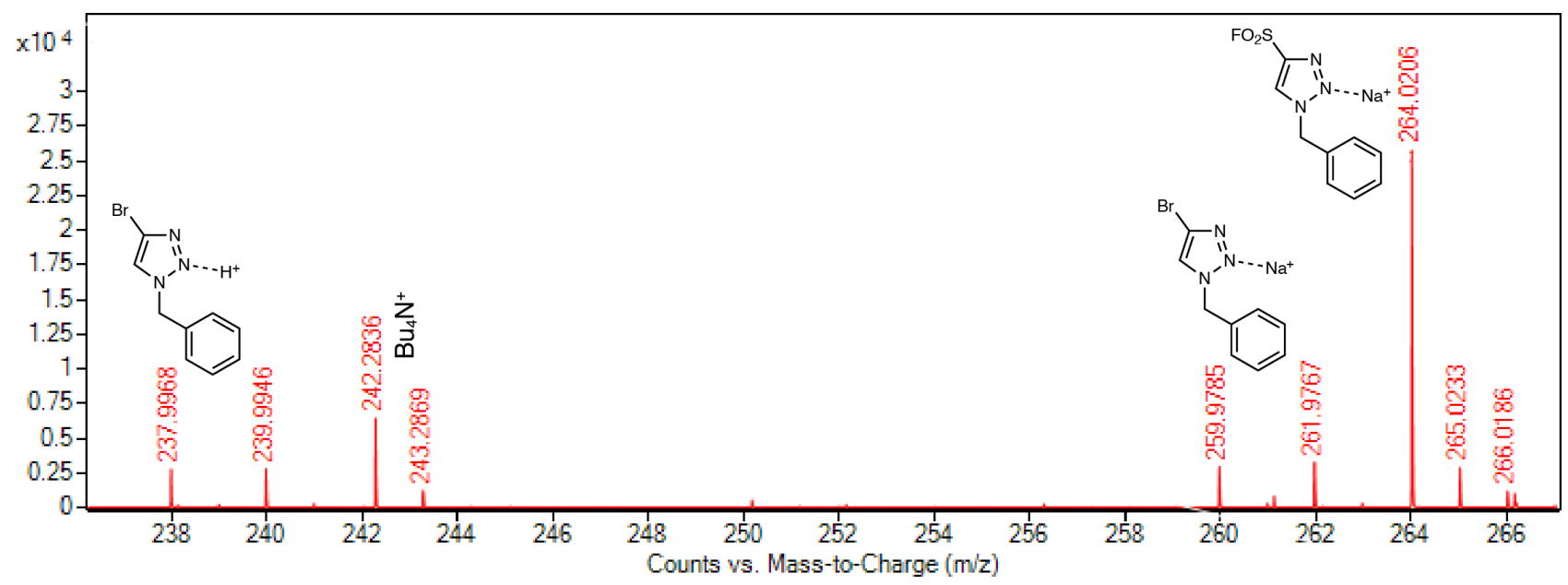

Figure S7. Fragment of the spectrum of 3:2 mixture of $\mathbf{3}$ and $\mathbf{4}$ ionized from pure MeCN.

As soon as water flow of $5 \mu \mathrm{L} / \mathrm{min}$ was turned on from the reference nebulizer, all the abundancies of analyzed products increased significantly. After adjusting flow rates $\left(\mathrm{MeCN}\right.$ solution $5 \mu \mathrm{L} / \mathrm{min} ; \mathrm{H}_{2} \mathrm{O}$ $50 \mu \mathrm{L} / \mathrm{min}$ ), and ionization parameters: for $[3+\mathrm{H}]^{+} \sim 500$ times increase and up to $\sim 20$ times for $[4+\mathrm{H}]^{+}$.

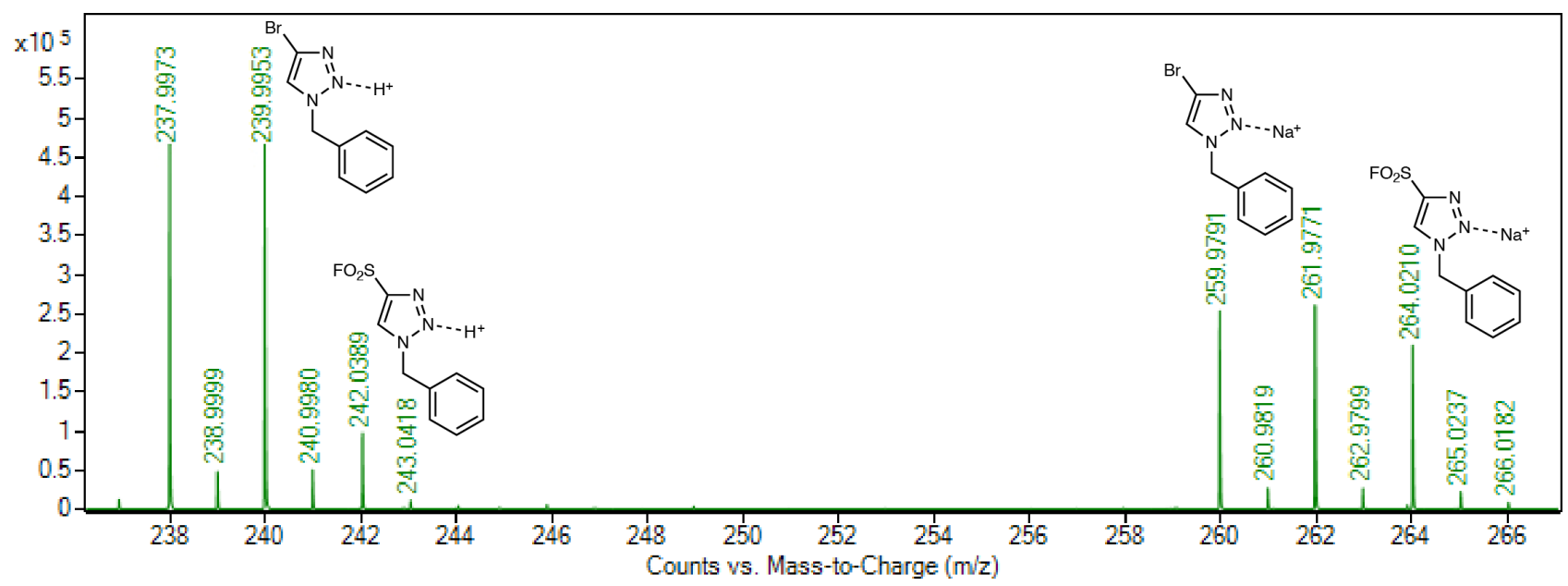

Figure S8. Fragment of the spectrum of 3:2 mixture of $\mathbf{3}$ and $\mathbf{4}$ ionized from MeCN with $5 \mu \mathrm{L} / \mathrm{min}$ flow of water sprayed from reference nebulizer. 


\section{Effect of ionization parameters}

Three major parameters that can affect the efficiency of the reaction in microdroplets are (i) flow rate of the mixture, (ii) flow rate of water (from reference nebulizer), and the pressure of nebulizing gas. In order to investigate the effect of three selected parameters reaction was examined at 2 and $5 \mu \mathrm{L} / \mathrm{min}$ flow with ramp of water flow rate at 10,15,20,25, and 35 psi pressure of nebulizing gas.

The reaction was studied in four solvents: $\mathrm{MeCN}, \mathrm{PhMe}, \mathrm{DCM}$ and DMF. In case of DMF, no reaction was observed. In cases of MeCN, PhMe, and DCM of the $\mathbf{3}$ was primary reaction product to be formed. Even though 4 was not clearly detected, noise abundance in the area of its signals was integrated to obtain selectivity plot. Ion abundances are reproducible within at least three replications. MeCN was a better solvent for ionization comparing to DCM or PhMe.

For all three solvents sum of intensities of all ions corresponding to the product ions were divided by flow rate of the reaction mixture for normalization purposes (to see the effect of the flow), and plotted versus water flow rate and nebulizing pressure (see figures below).
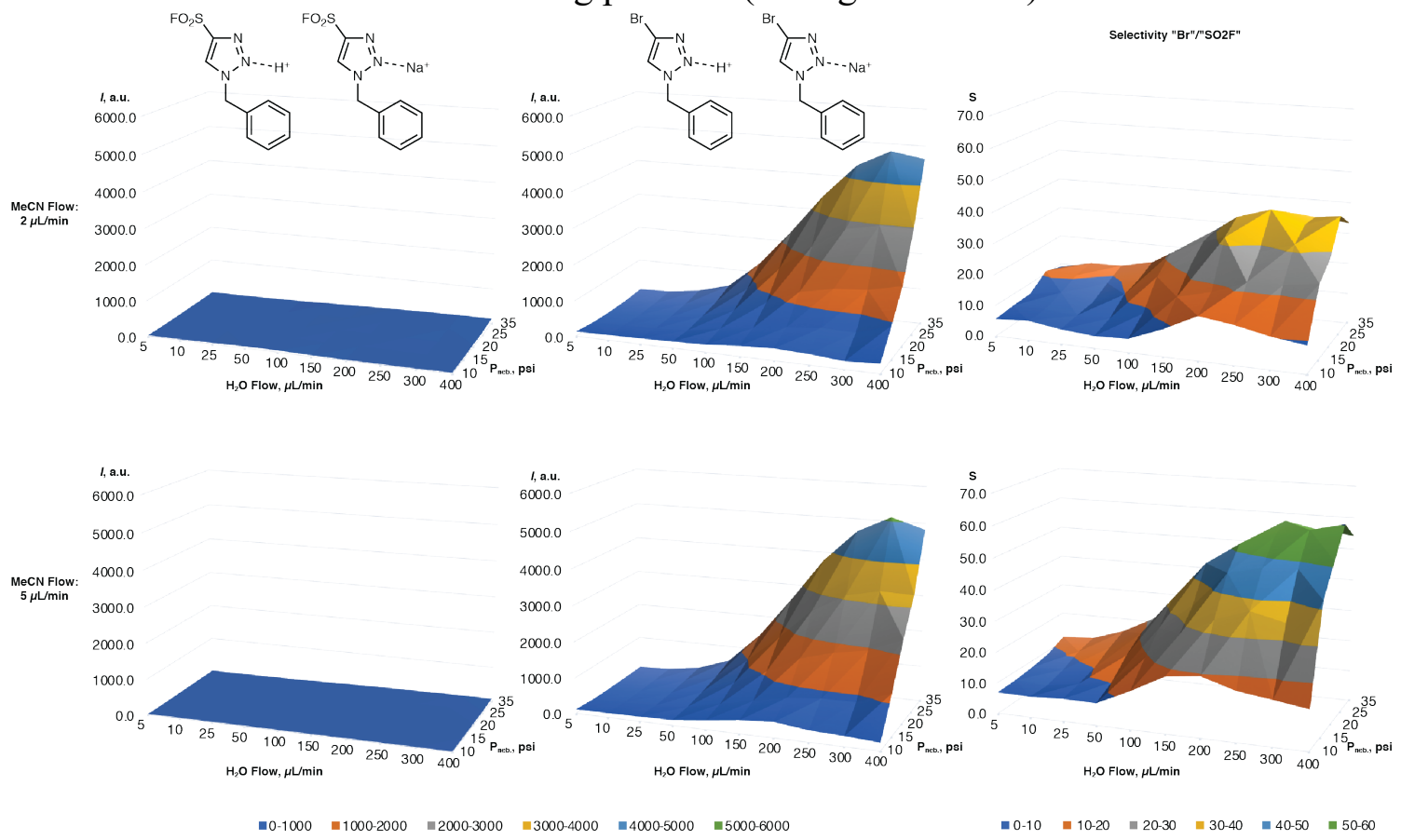

Figure S9. Normalized ion abundances for $\mathbf{3}$ and $\mathbf{4}$ and selectivity of the reaction in $\mathrm{MeCN}$ in microdroplets of water depending on the water flow rate and nebulizing pressure. 

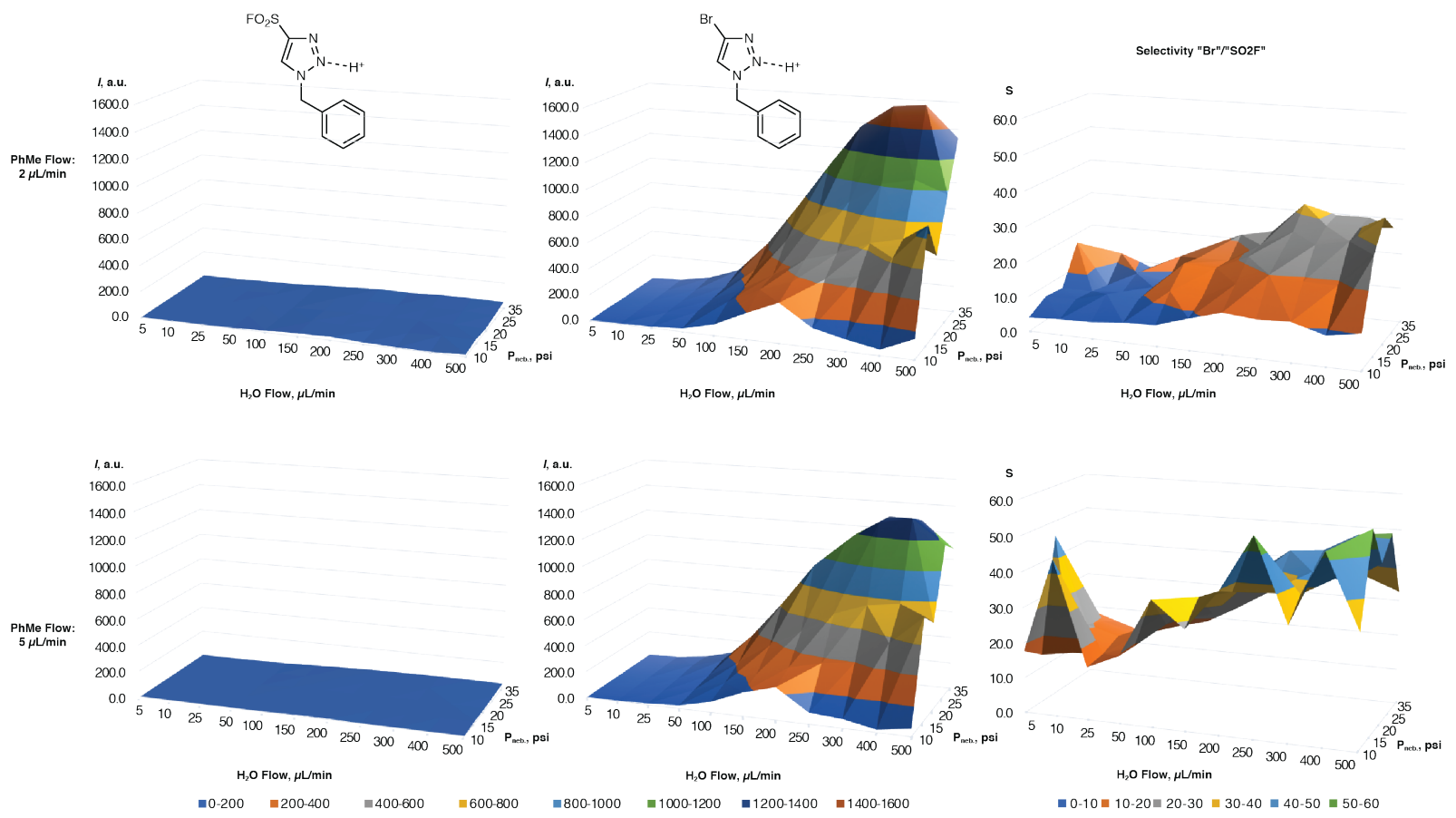

Figure S10. Normalized ion abundances for $\mathbf{3}$ and $\mathbf{4}$ and selectivity of the reaction in $\mathrm{PhMe}$ in microdroplets of water depending on the water flow rate and nebulizing pressure.
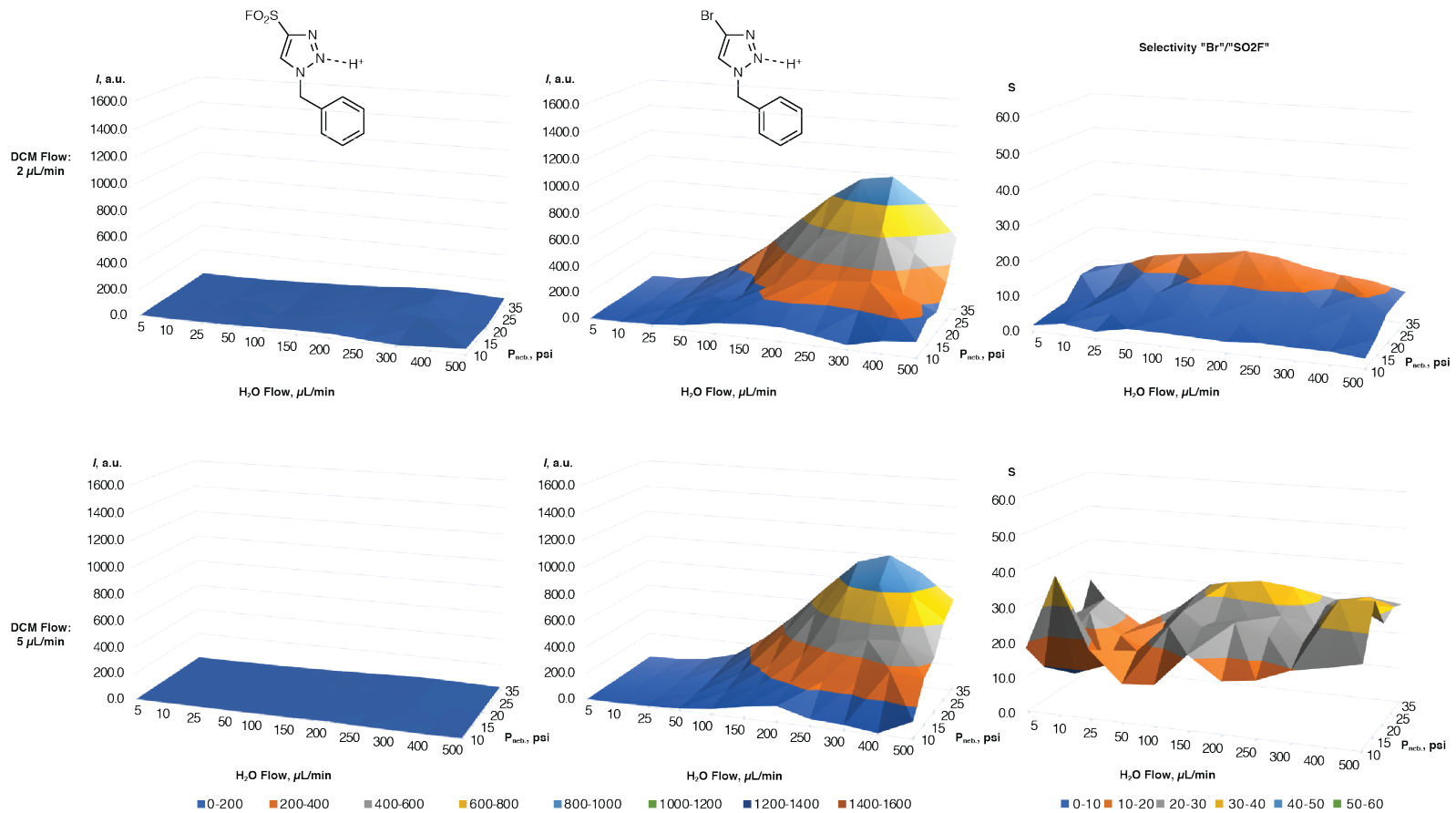

Figure S11. Normalized ion abundances for $\mathbf{3}$ and $\mathbf{4}$ and selectivity of the reaction in DCM in microdroplets of water depending on the water flow rate and nebulizing pressure.

As can be concluded from the graphs, reaction mixture flow rate does not affect the reaction rate, however greater ionization is a result. Thus, for the further studies, $5 \mu \mathrm{L} / \mathrm{min}$ flow was used. In the case of $\mathrm{MeCN}$, at water flow rate above $200 \mu \mathrm{L} / \mathrm{min}$ and nebulizing pressure above $20 \mathrm{psi}$, the selectivity exceeds 50:1. Similar trend was observed for toluene and DCM, however, lower ion current leads to less 
smooth selectivity plot. The reaction occurs in the ion source, and the time of the reaction is the time microdroplets travel from the nebulizer to the MS inlet.

\section{Additional experimental notes}

- Ion abundance of $[3+\mathrm{H}]^{+}$formed in the source linearly depends on the $\mathrm{pH}$ value in the range we examined (2.66 - 5.95). MilliQ water used in these studies has $\mathrm{pH}$ of $\sim 5.9$ due to high solubility of $\mathrm{CO}_{2}$.

- We inspected ionization efficiency using $\mathrm{D}_{2} \mathrm{O}$ versus $\mathrm{H}_{2} \mathrm{O}$ at $300 \mu \mathrm{L} / \mathrm{min}$ flow rate and $5 \mu \mathrm{L} / \mathrm{min}$ flow rate of standard solution of 3. Bromo-triazole at $210 \mathrm{nM}$ demonstrated 1.6-times better ionization in $\mathrm{H}_{2} \mathrm{O}$. This difference almost disappeared at higher concentration, as $2 \mu \mathrm{M}$ solution was only 1.1-times better ionizable in $\mathrm{H}_{2} \mathrm{O}$ over $\mathrm{D}_{2} \mathrm{O}$ (Figure $\mathrm{S} 12$ ). Thus, ionization using $\mathrm{D}_{2} \mathrm{O}$ does not interfere significantly with observing the water isotope effect of 8.8 , because different size of microdroplets or less efficient $\mathrm{D}^{+}$transfer.

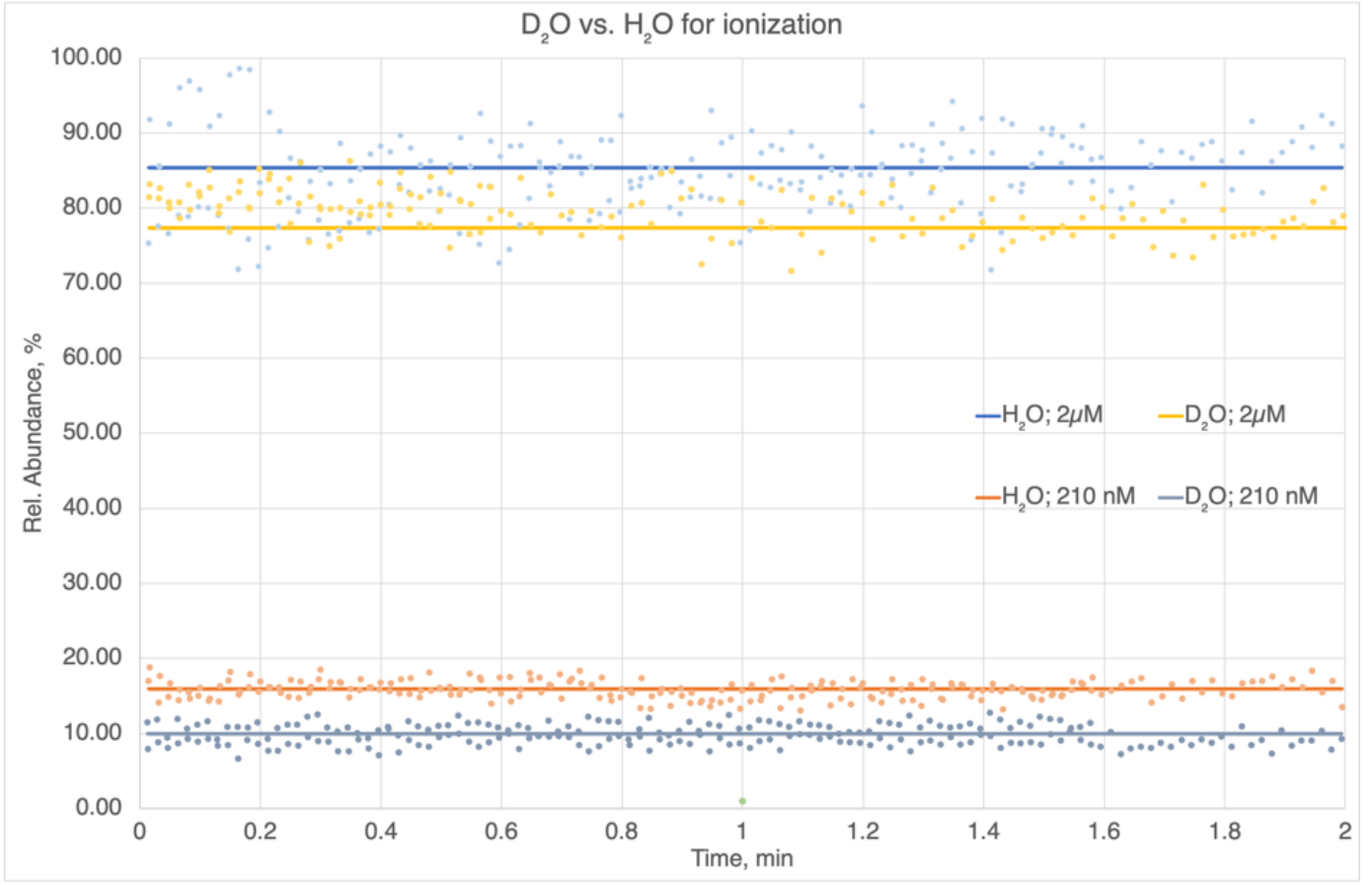

Figure S12. Normalized ion abundance of $\mathbf{3}(210 \mathrm{nM}$ or $2 \mu \mathrm{M})$ when $\mathrm{H}_{2} \mathrm{O}$ or $\mathrm{D}_{2} \mathrm{O}$ used.

- The stability of Br-ESF (2) under experimental conditions was evaluated by nebulizing $1 \mathrm{~mL}$ of $2 \mathrm{mM}$ solution of 2 into ionization chamber accompanied by $300 \mu \mathrm{L} / \mathrm{min}$ flow rate of water. The exhaust of the ionization chamber was equipped with a glass funnel, leading into a flask filled with glass wool. After spraying whole solution, organic content was extracted with $1 \mathrm{~mL}$ of DMC and analyzed by GCQ-MS/FID in scan and SIM modes. Intact 2 was reliably detected (Figures S13, S14), while no decomposition products were observed. 


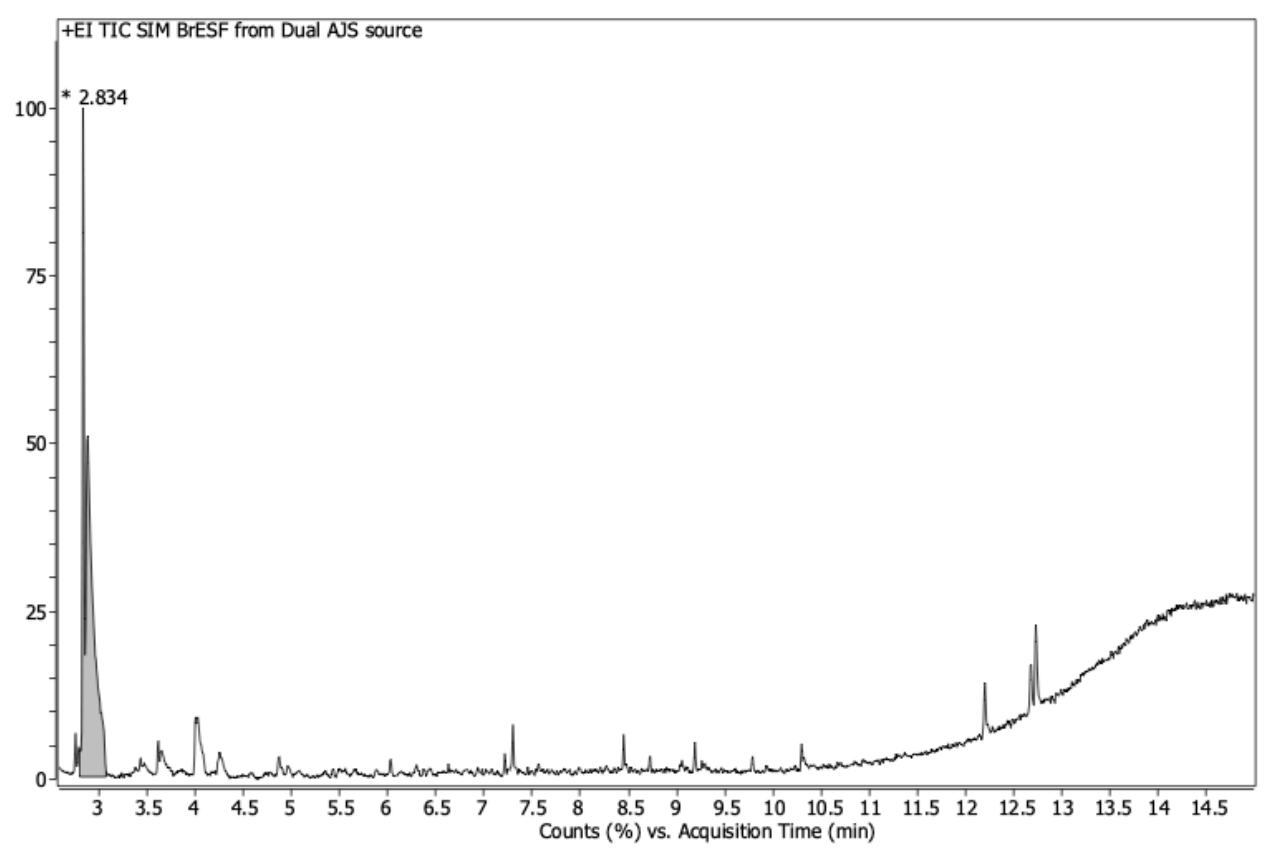

Figure S13. GC-MS chromatogram of extract obtained after collecting 2 sprayed into ionization chamber.

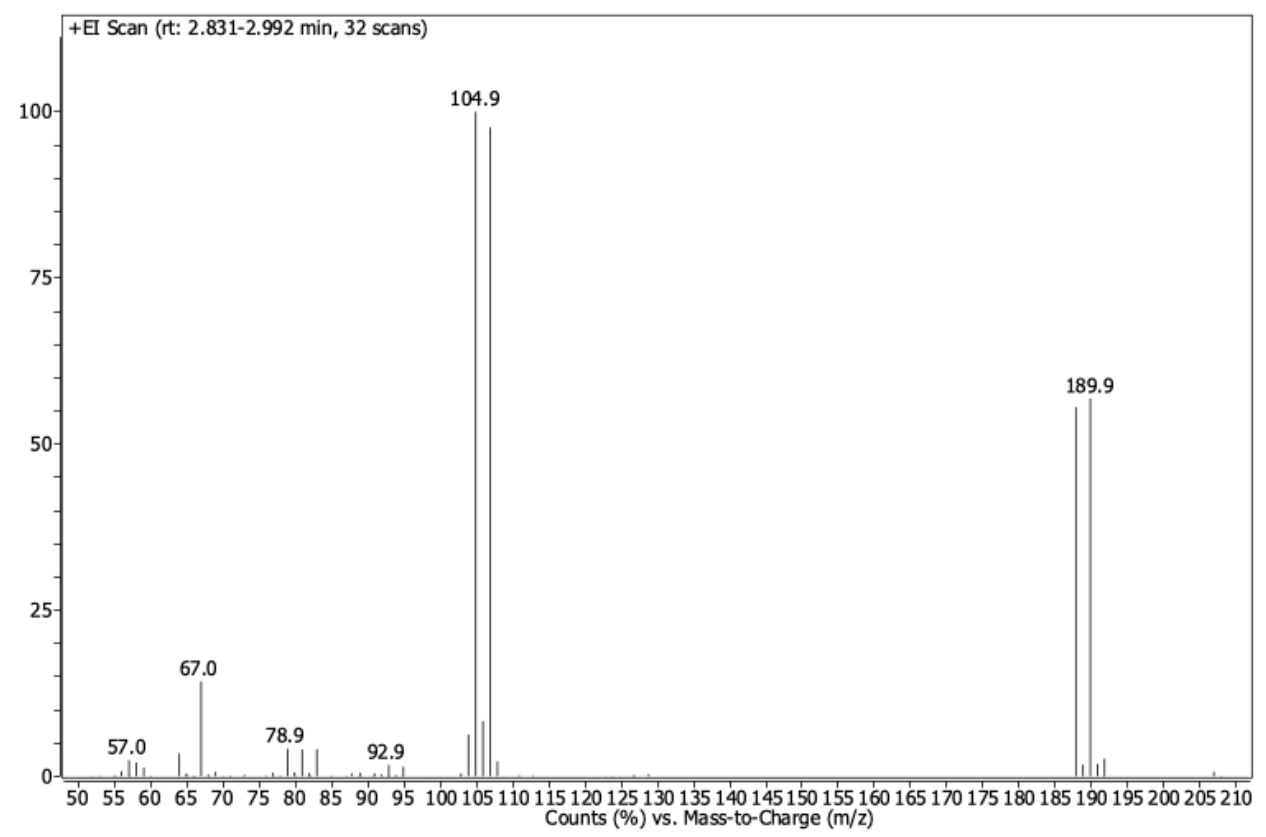

Figure S14. EI-Q-MS spectrum of 2.

- To examine whether there is a trend of the changed size of droplets in the plume and to confirm the formation of the "on-water" layer of $\mathrm{BnN}_{3}(\mathbf{1})$, we used inverted microscope Leica DMi8 (Leica, Wetzlar, Germany), equipped with a Leica DFC365FX digital camera, using 40x objective lenses. A precleaned glass slide was quickly introduced into the intersection of two plumes (organic and water), immediately pulled out and transferred to the microscope.

All observed droplets appeared larger than ones in the plume. At 10 psi, droplets were the largest, and their size decreased when nebulizing pressure increased (up to $35 \mathrm{psi}$ ). At 10 psi droplets were $>1 \mathrm{~mm}$ in size, whereas at $35 \mathrm{psi},<0.5 \mathrm{~mm}$. We were able to image droplets because of an organic layer of 1 (Figure S15, S16) covering the water droplet. 


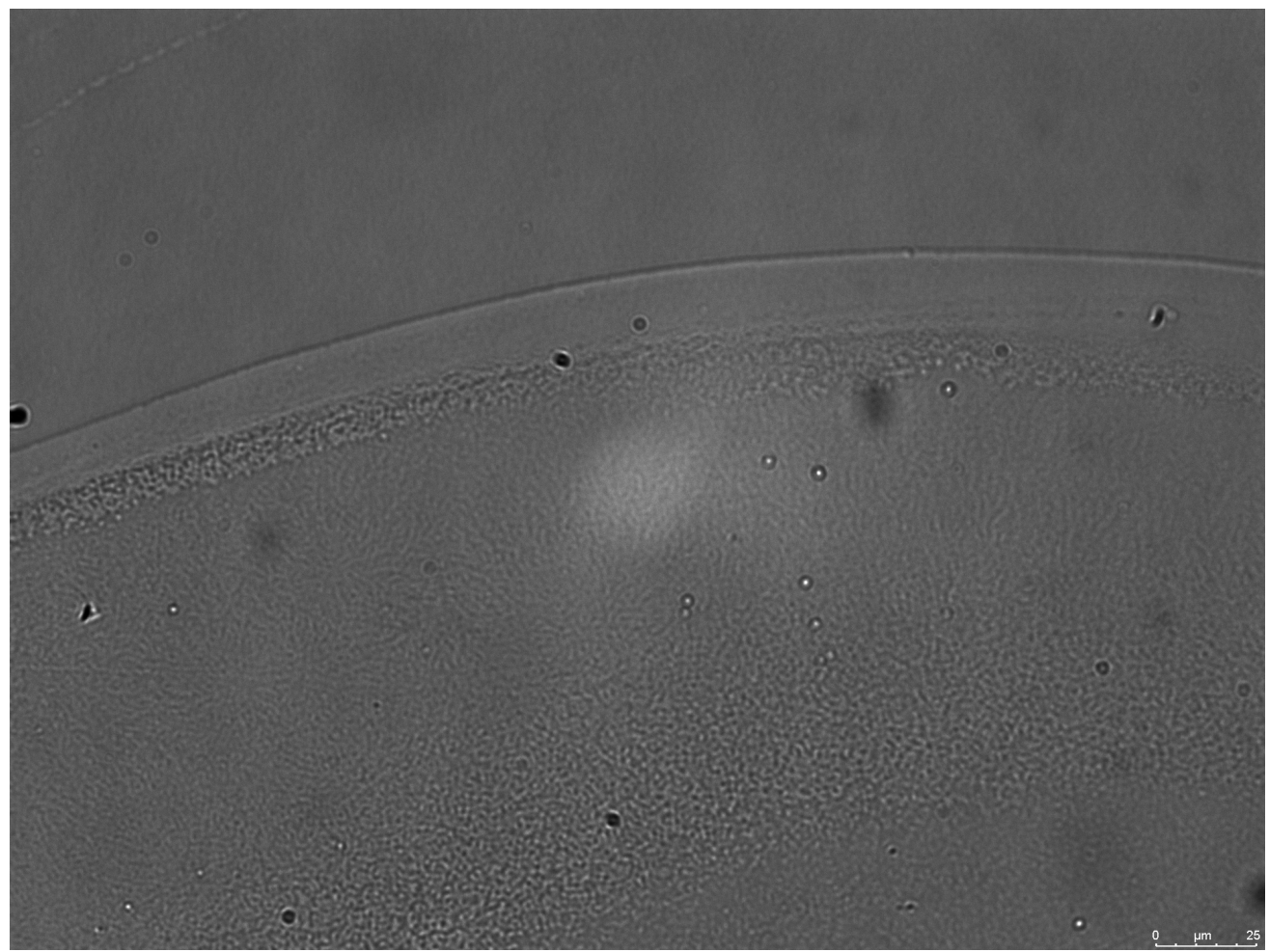

Figure S15. Edge of a dried water droplet covered with $\mathrm{BnN}_{3}$ thin layer formed at the intersection of water and organic plumes at 10 psi nebulizing pressure.

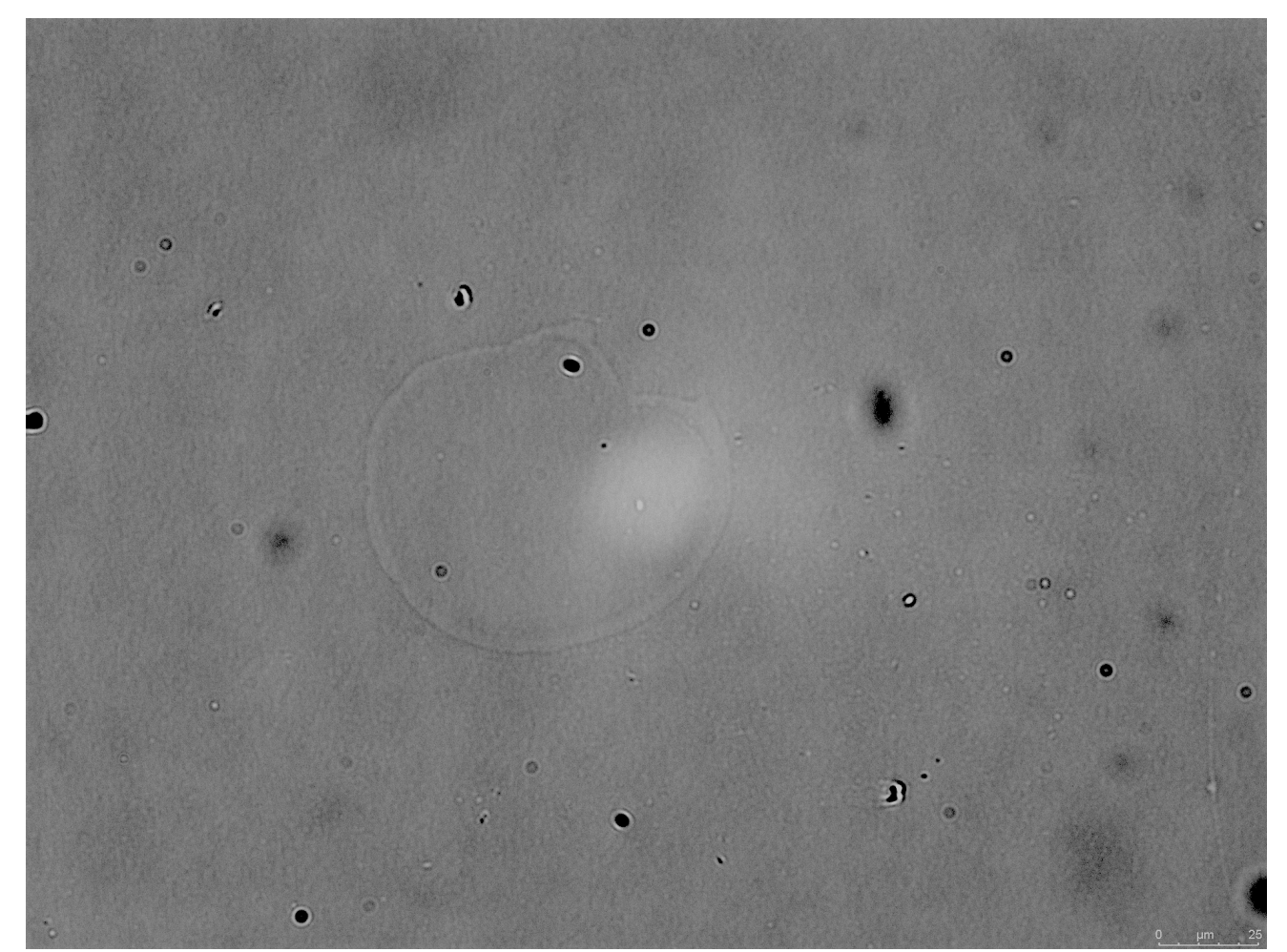

Figure S16. Dried water droplet covered with $\mathrm{BnN}_{3}$ thin layer formed at the intersection of water and organic plumes at 35 psi nebulizing pressure. 


\section{Calibration curves}

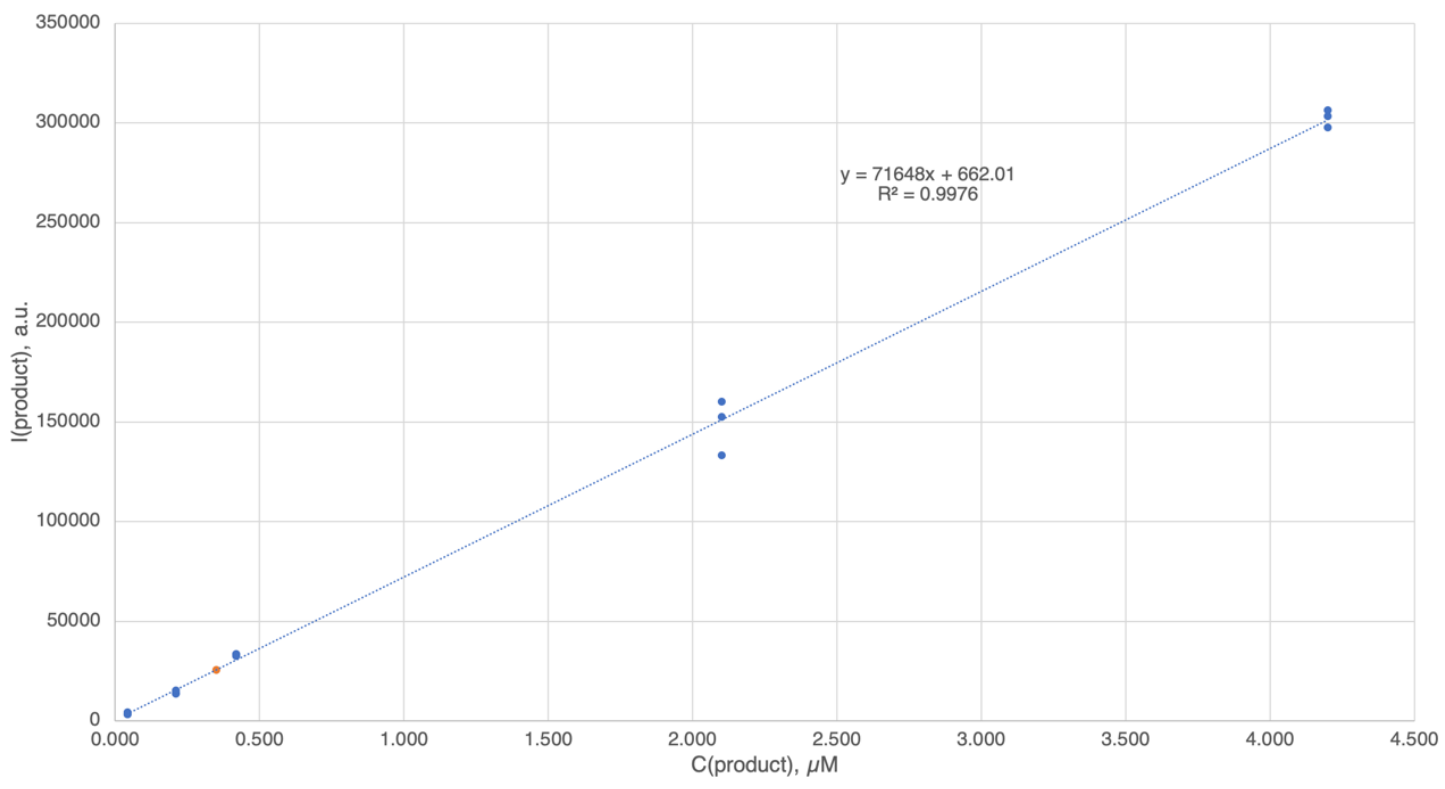

Figure S17. Representative calibration curve for 3 sprayed from $\mathrm{MeCN}$ solution and water flow rate of $300 \mu \mathrm{L} / \mathrm{min}$. Orange point represents observed reaction outcome under the same conditions.

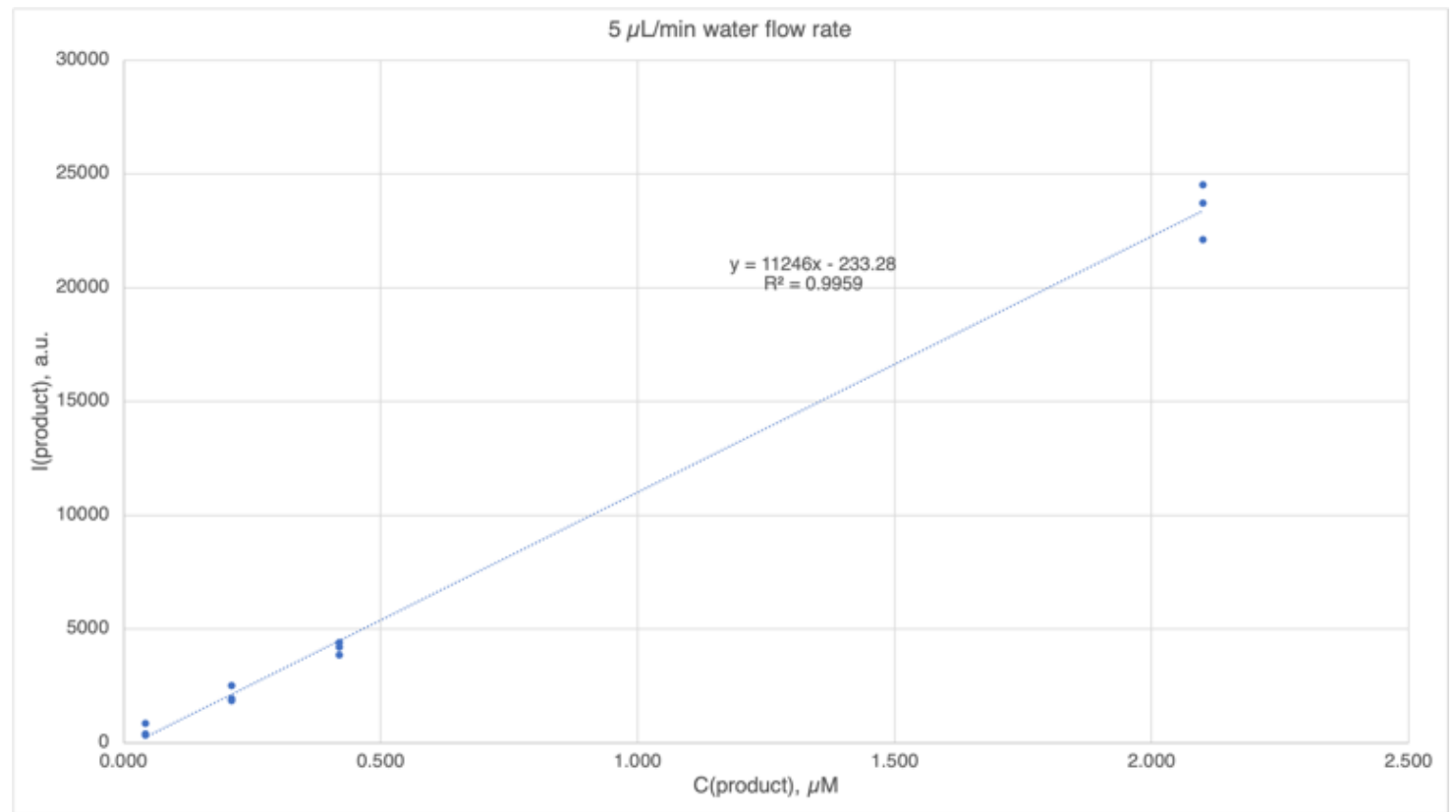

Figure S18. Representative calibration curve for 3 sprayed from $\mathrm{MeCN}$ solution and water flow rate of $5 \mu \mathrm{L} / \mathrm{min}$. 


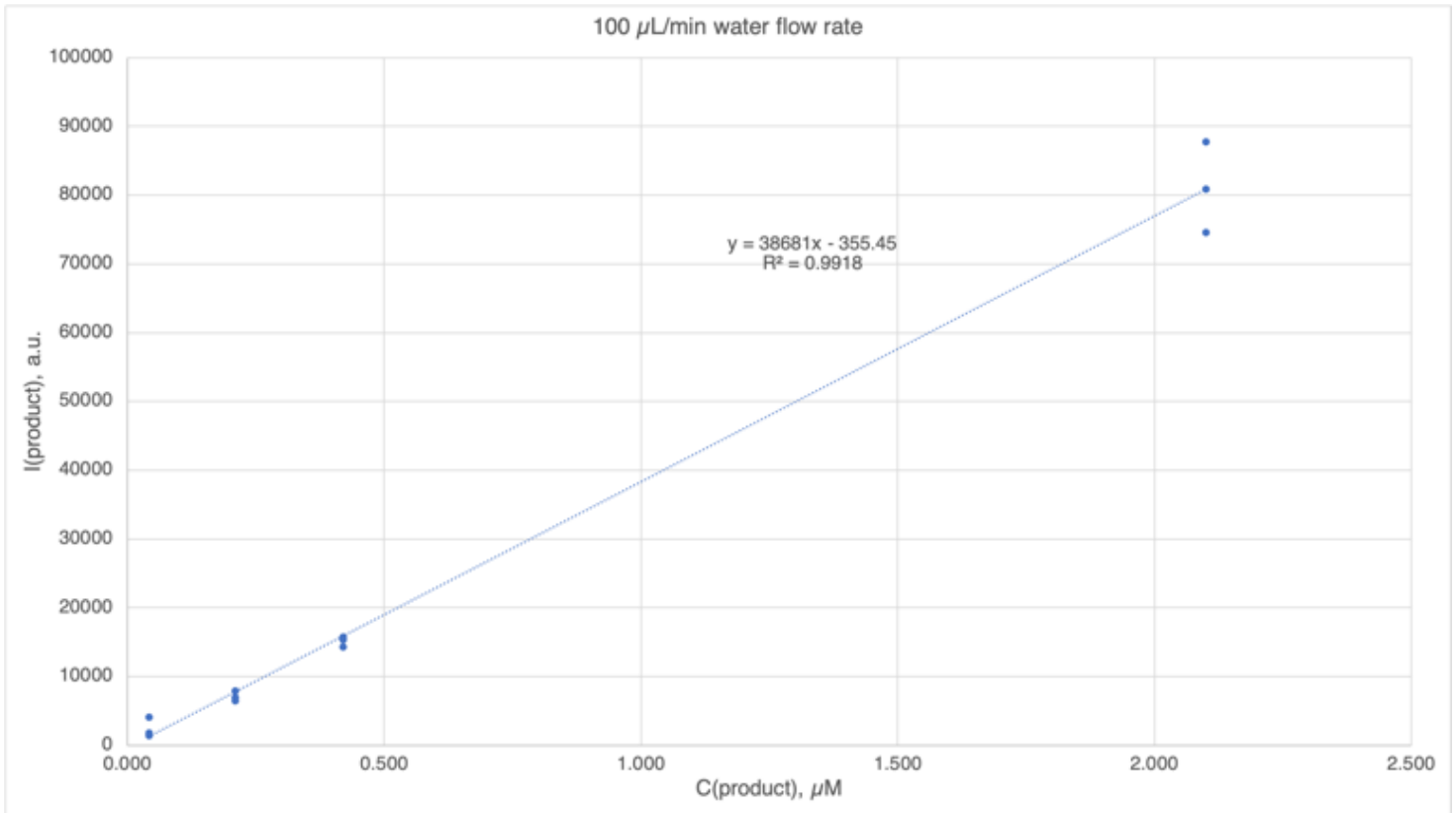

Figure S19. Representative calibration curve for 3 sprayed from $\mathrm{MeCN}$ solution and water flow rate of $100 \mu \mathrm{L} / \mathrm{min}$.

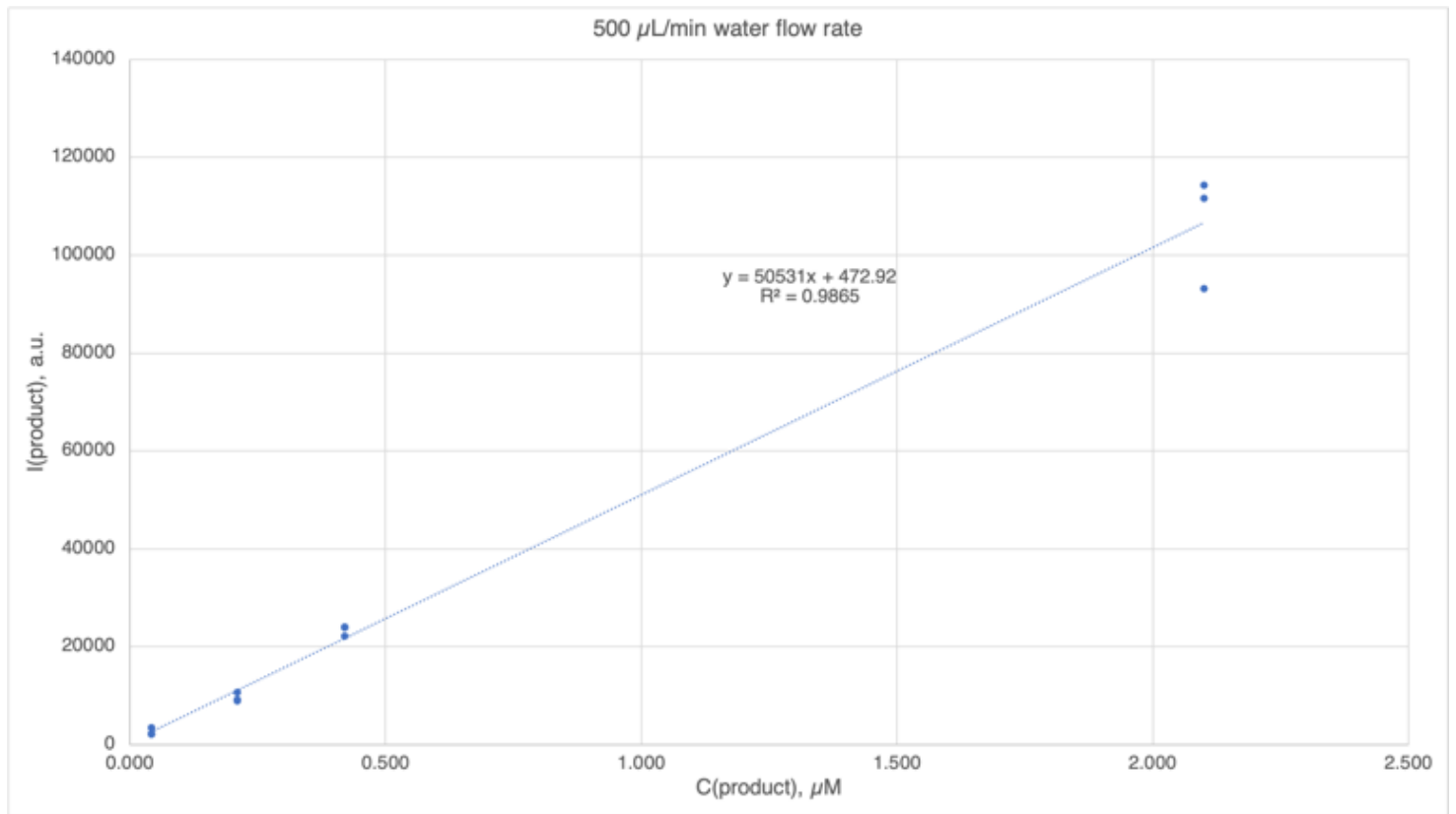

Figure S20. Representative calibration curve for $\mathbf{3}$ sprayed from $\mathrm{MeCN}$ solution and water flow rate of $500 \mu \mathrm{L} / \mathrm{min}$.

For acetonitrile, concentration point of $4.2 \mu \mathrm{M}$ lies slightly off calibration for water flow rates below $200 \mu \mathrm{L} / \mathrm{min}$. This observation may be explained by poor solubility of $\mathbf{3}$ in water: at lower organic : water ratios part of the product precipitates and is not ionized. 


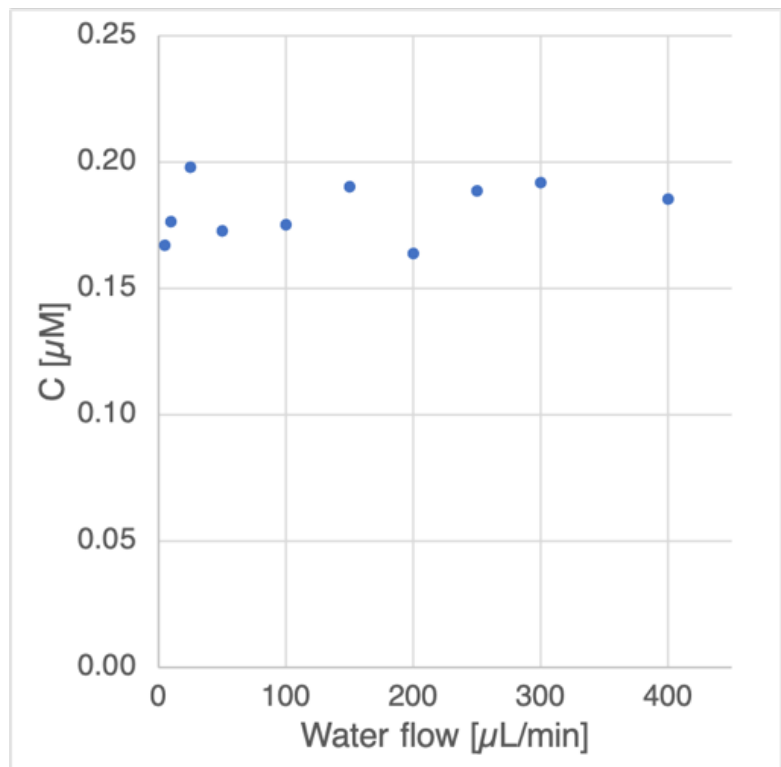

Figure S21. Concentration of $\mathbf{3}$ (sprayed from $\mathrm{MeCN}$ ) recalculated for $210 \mathrm{nM}$ solution at different water flow rates applied.

Concentrations of 3 were calculated based on the abundances of $210 \mathrm{nM}$ sample injected at different water flow rates (Figure S21). Linear constant trend of response suggests signal of $\mathbf{3}$ to increase in the presence of water, but ionization mechanism does not change, whereas analyzed reaction yields at different flow rates have a saturation profile.

A calibration curve was also constructed in toluene, in which $\mathbf{3}$ was still easily ionized. However, insource formation of product 3 in toluene did not exceed $0.035 \mu \mathrm{M}$ (100 times less than in acetonitrile), suggesting the importance of the properties of the organic solvent for the overall reaction efficiency.

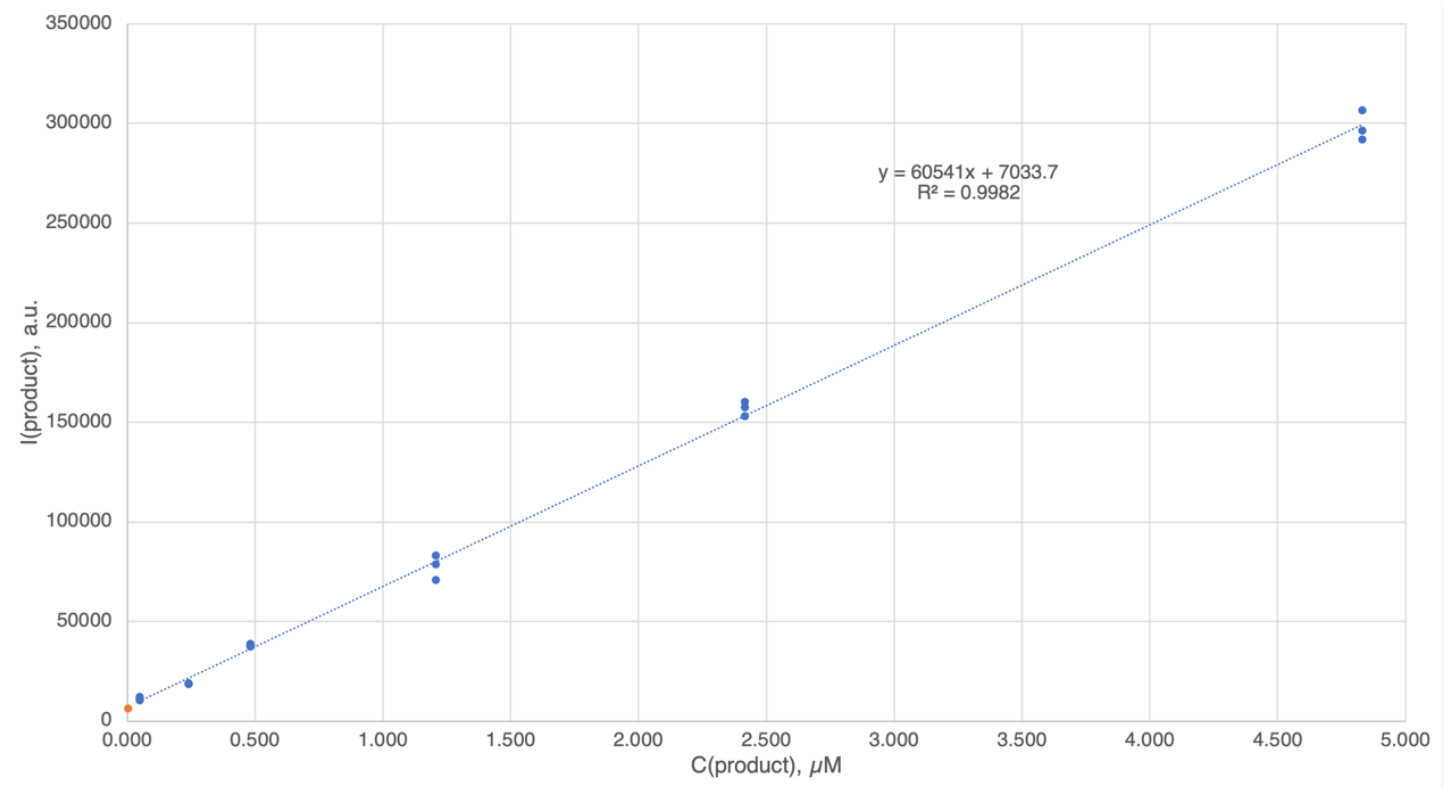

Figure S22. Representative calibration curve for 3 sprayed from PhMe solution and water flow rate of $300 \mu \mathrm{L} / \mathrm{min}$. Orange point represents observed reaction outcome under the same conditions. 


\section{Analysis of collected spray content}

Reaction in the intersection of two sprays was analyzed by GC-MS techniques after extraction of organic content with DCM. Along with recovered starting materials, only Br-triazole 3 was detected. No signals corresponding to triazole 4 were observed. Control experiments of collecting the reaction mixture in the absence of water and injection of reaction mixture in $\mathrm{MeCN}$ after $2 \mathrm{~h}$ incubation at r.t. showed no formation of any products.

Fusion of two sprays:

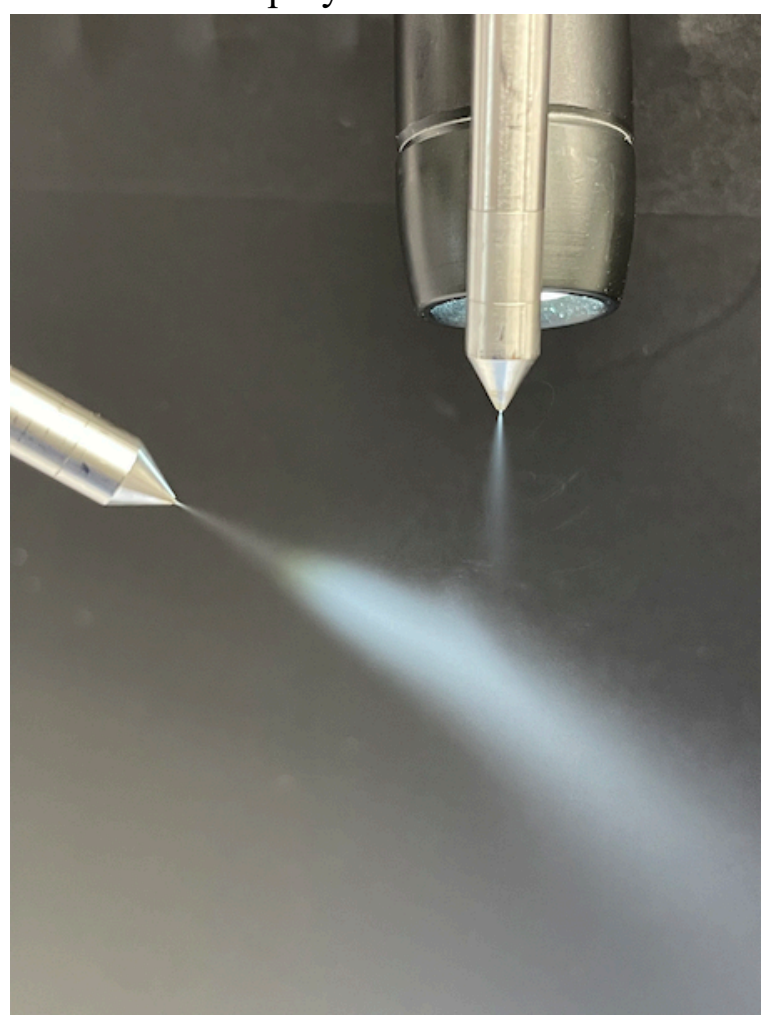

Figure S23. Fusion of two sprays: vertical spray - MeCN $10 \mu \mathrm{L} / \mathrm{min}$ flow, angle spray $-\mathrm{H}_{2} \mathrm{O} 300 \mu \mathrm{L} / \mathrm{min}$ flow at 35 psi of nebulizing pressure. 


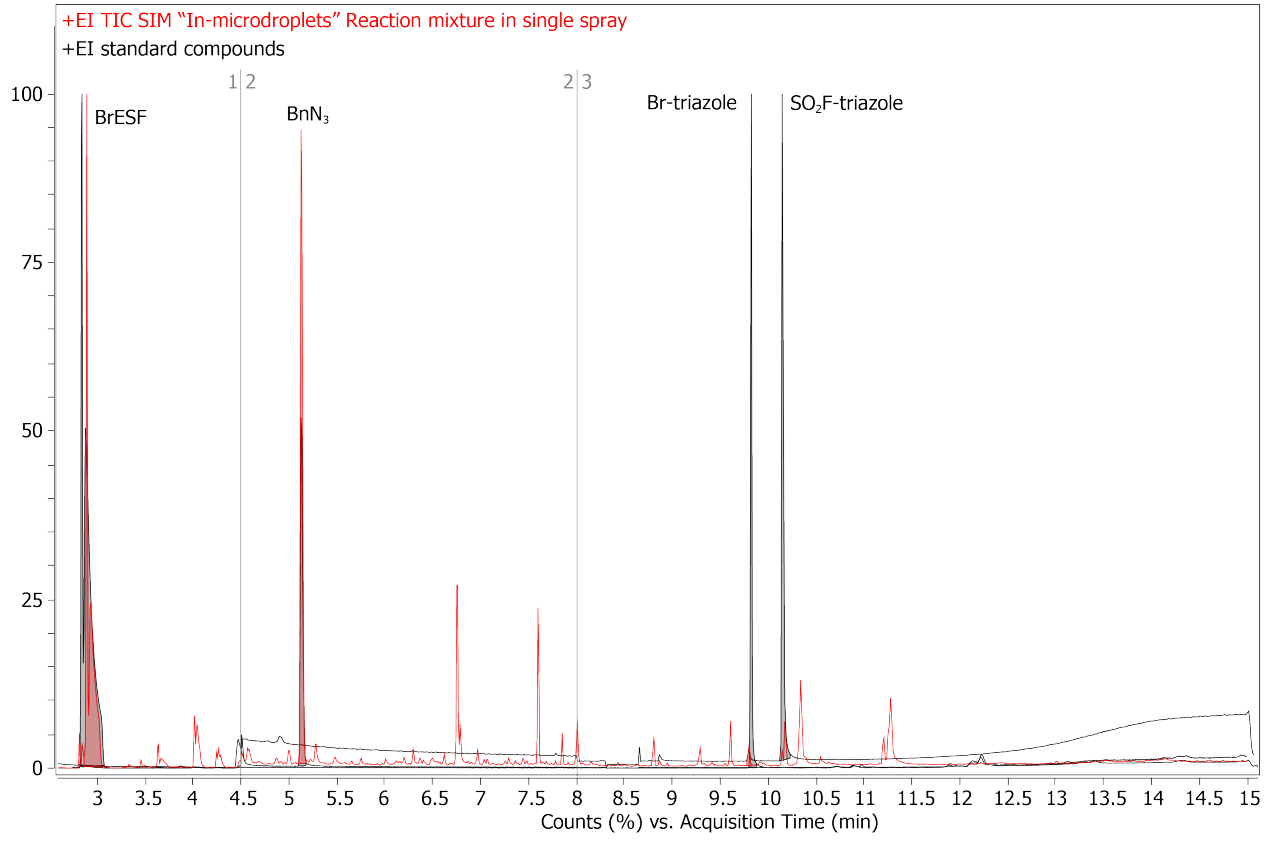

Figure S24. GC-MS (SIM) chromatogram of the extract obtained after collecting reaction mixture sprayed onto water plume in the collecting setup. Red - extracted reaction mixture, containing starting $\mathrm{Br}-\mathrm{ESF}, \mathrm{BnN}_{3}$, and selectively $\mathrm{Br}$-triazole.

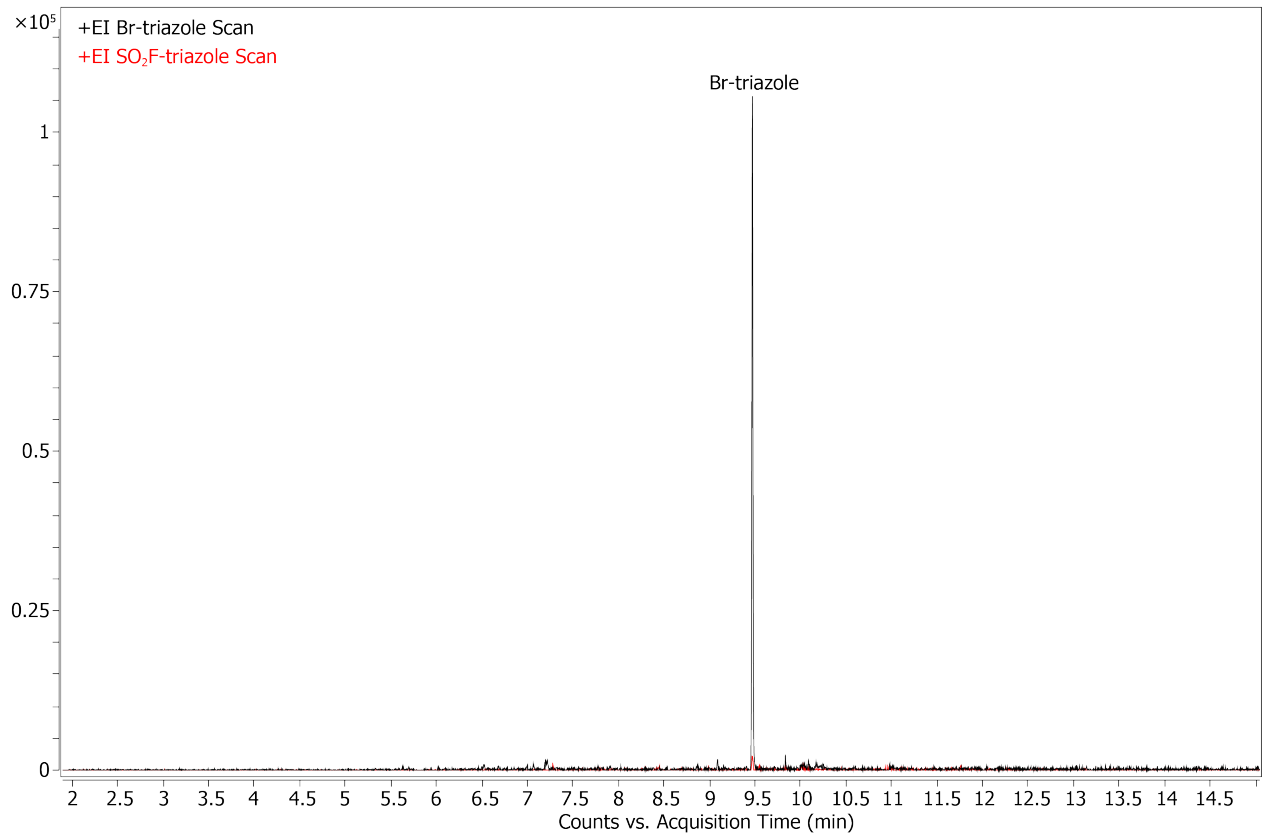

Figure S25. GC-MS (qToF) extracted ion chromatograms of unique ions of Br-triazole 3 (black) - observed; and $\mathrm{SO}_{2} \mathrm{~F}-$ triazole 4 (red) - not observed. The extract obtained after collecting reaction mixture sprayed onto water plume in the collecting setup. 


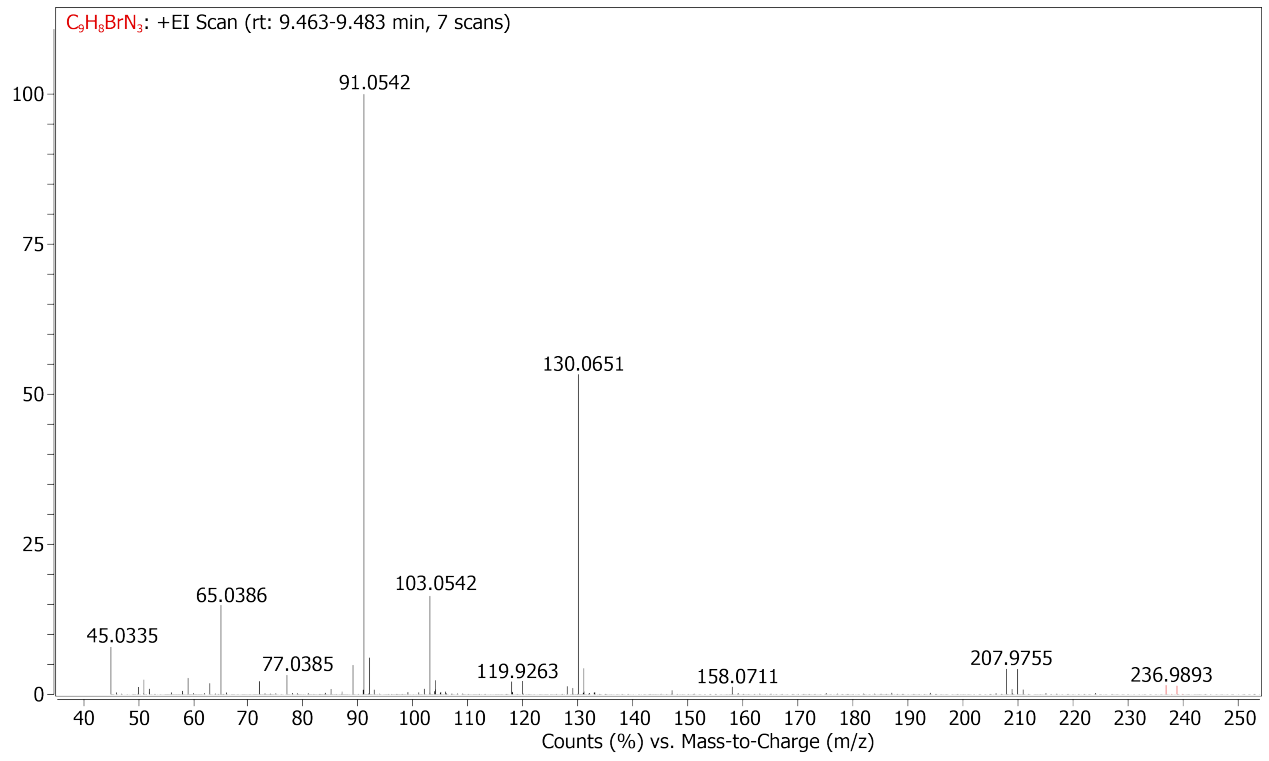

Figure S26. EI-qToF-MS high-resolution mass spectrum of Br-triazole 3 observed in the in the extract obtained after collecting reaction mixture sprayed onto water plum in the collecting setup. For the molecular ion (in red): calcd for $\mathrm{C}_{9} \mathrm{H}_{8} \mathrm{BrN}_{3}$ $[\mathrm{M}]^{+\bullet} \mathrm{m} / \mathrm{z} 236.9897$, found $\mathrm{m} / \mathrm{z} 236.9893(\Delta=1.7 \mathrm{ppm})$.

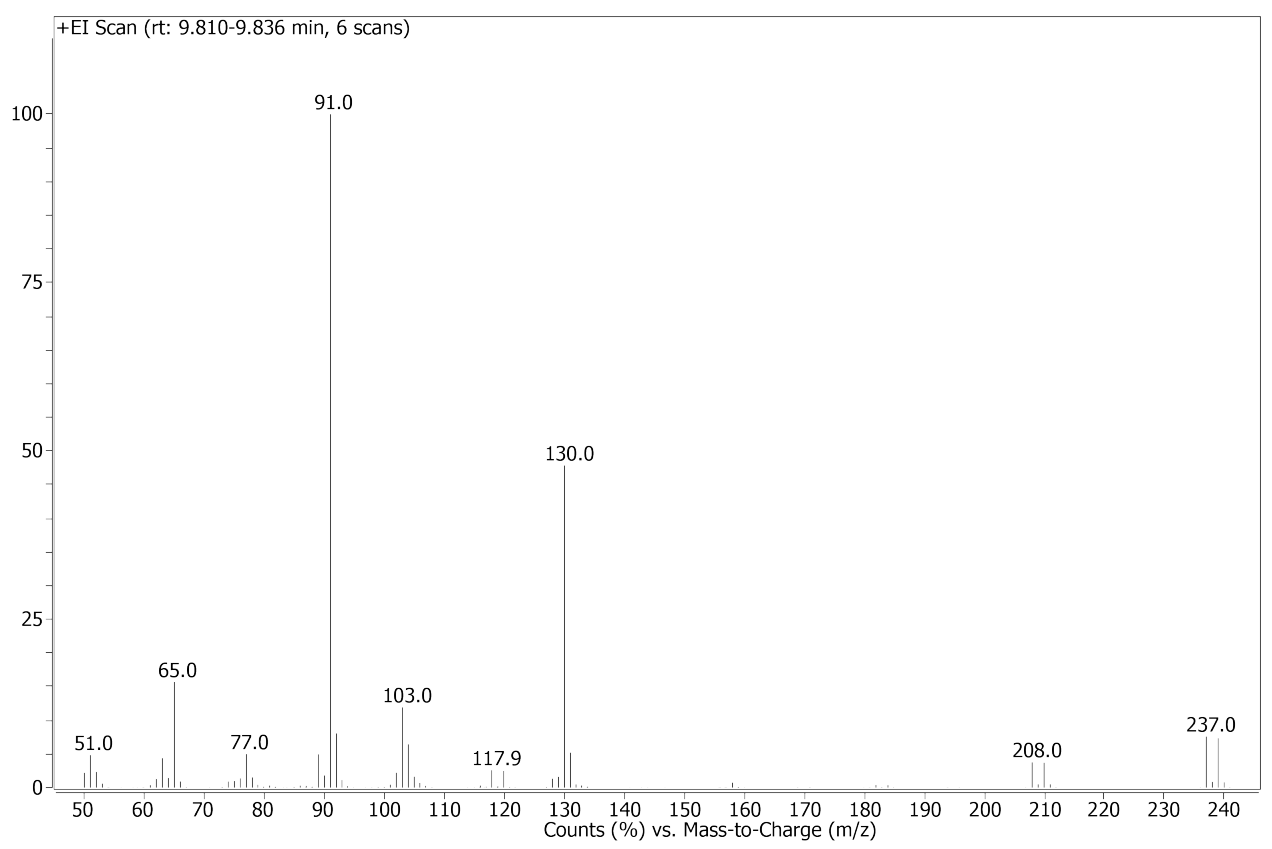

Figure S27. EI-Q-MS mass spectrum of standard sample of Br-triazole 3 observed. 


\section{Computational data}

Cycloaddition transition state (10TS) suggests that this stage is one-step asynchronous in nature. The Natom at the benzylic position attacks $\beta$-carbon of Br-ESF, which is followed by triazoline ring closure on the other side. Activation enthalpy is $+13.0 \mathrm{kcal} / \mathrm{mol}$ for the explicit solvation model, which is feasible for mild conditions (all transition states were found using growing string method).

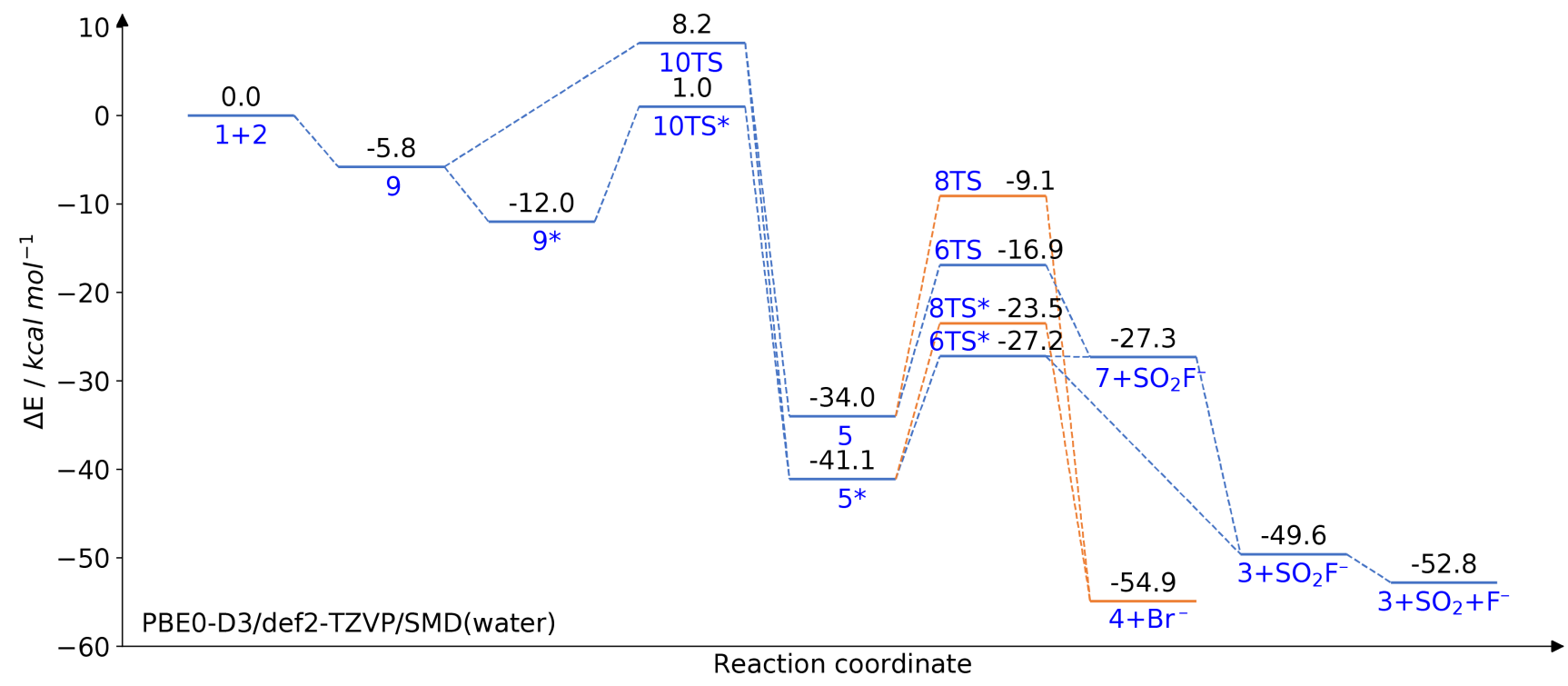

Figure S28. DFT calculated potential energy surface (in $\mathrm{kcals} / \mathrm{mol}$ ) for implicit and explicit (two molecules, structures denoted with *) water solvation at the PBE0-D3/def2-TZVP/SMD(water) level of theory.

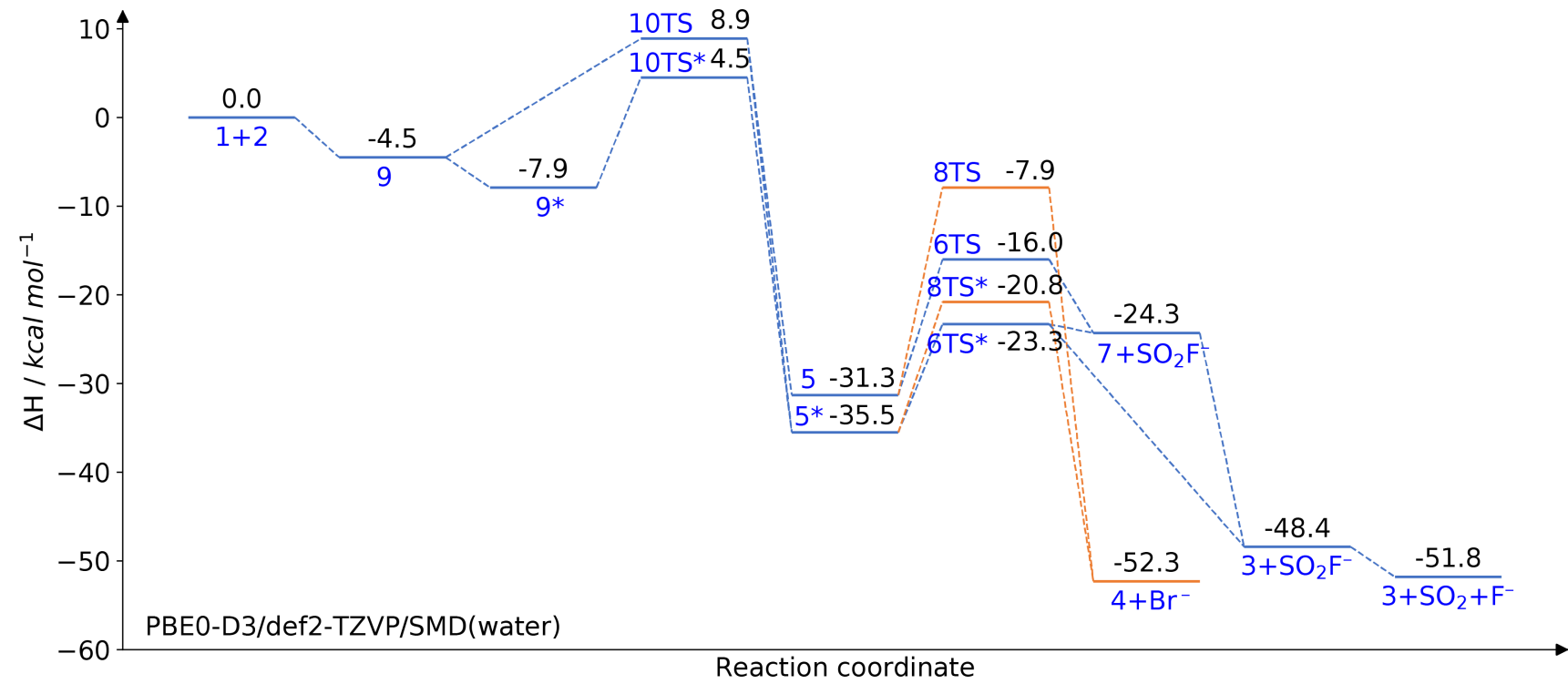

Figure S29. DFT calculated enthalpy surface (in kcals/mol) for implicit and explicit (two molecules, structures denoted with *) water solvation at the PBE0-D3/def2-TZVP/SMD(water) level of theory. 


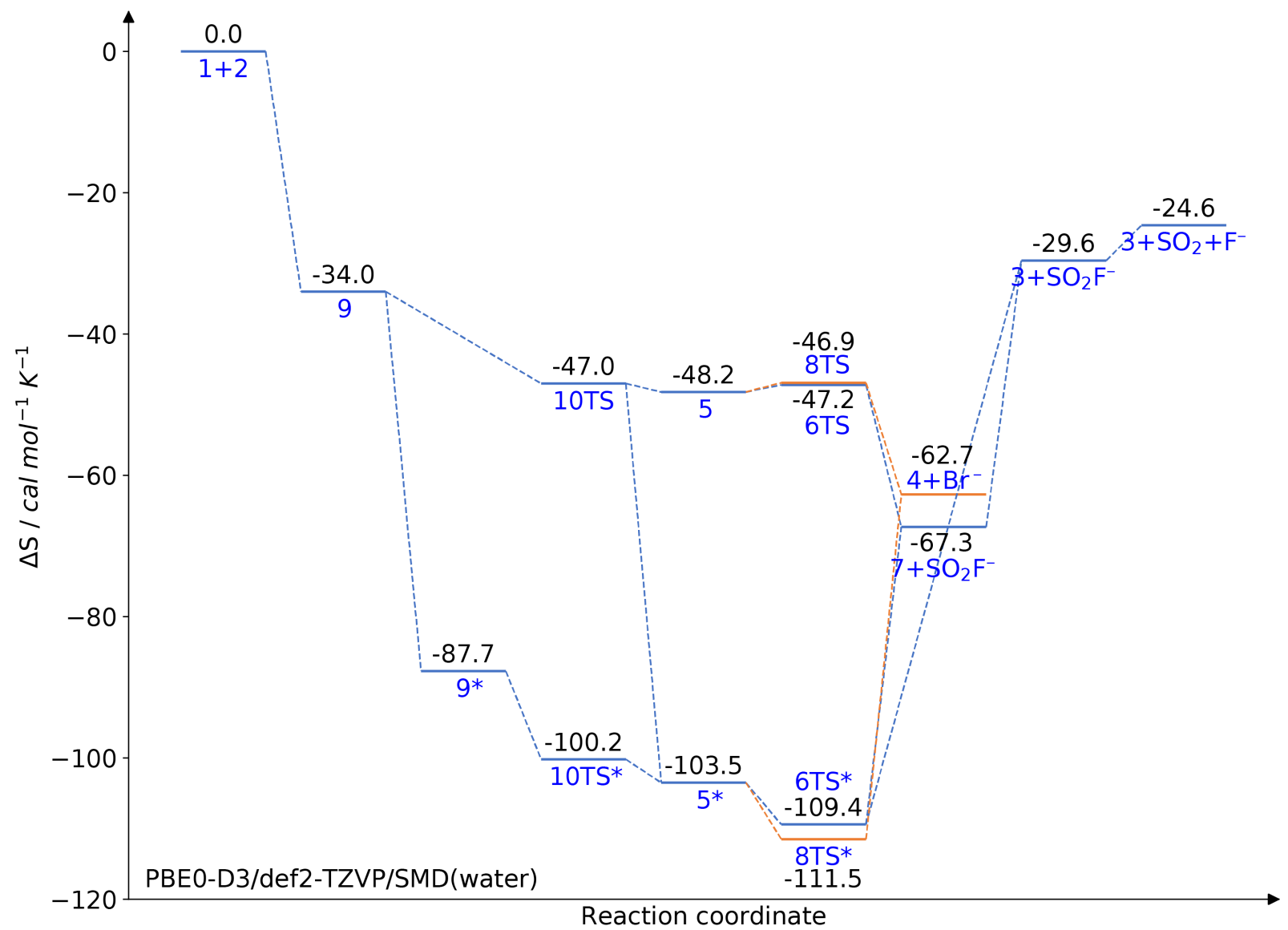

Figure S30. DFT calculated entropy surface (in kcals/mol) for implicit and explicit (two molecules, structures denoted with *) water solvation at the PBE0-D3/def2-TZVP/SMD(water) level of theory.

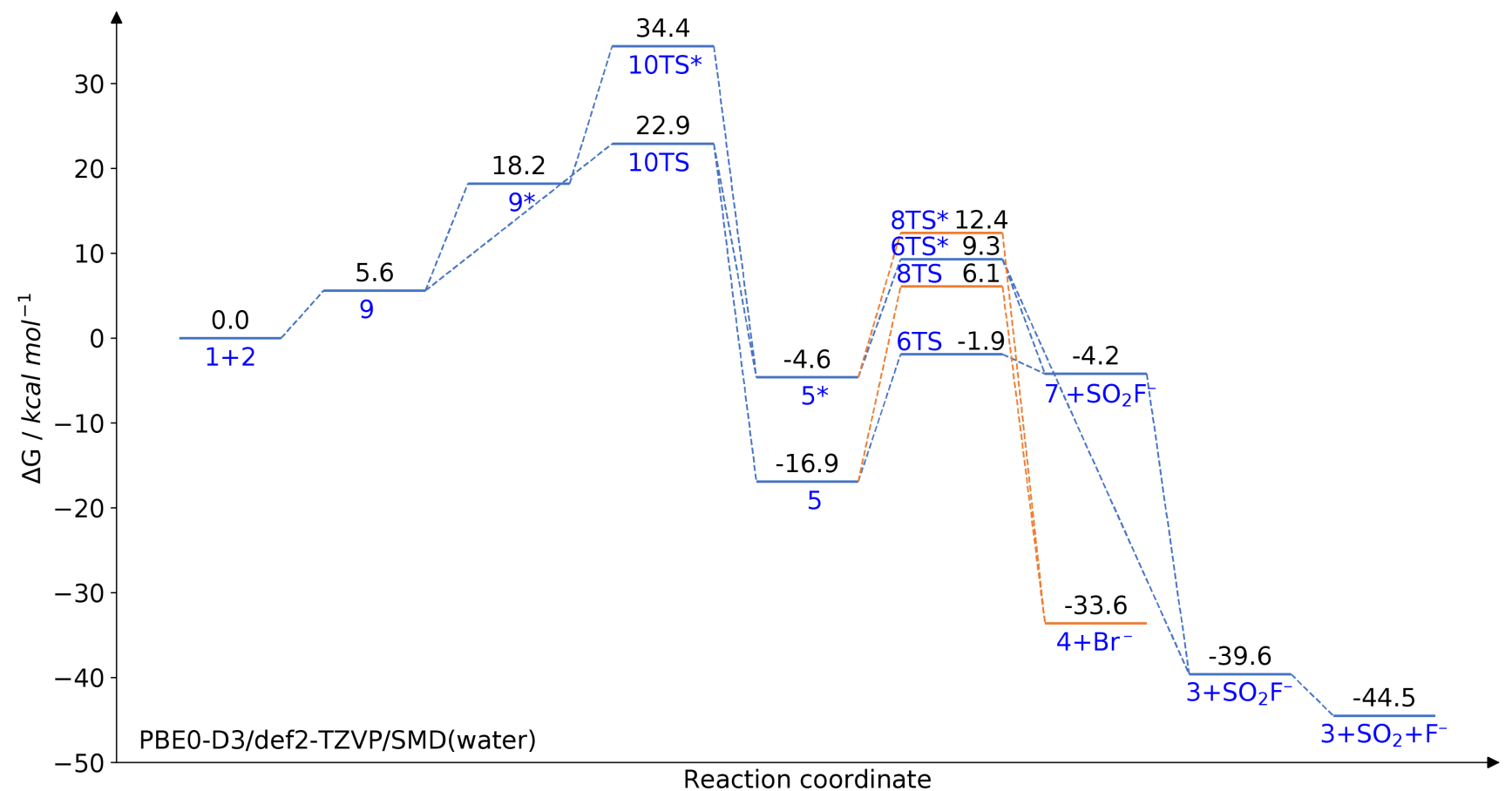

Figure S31. DFT calculated Gibbs free energy surface (in kcals/mol) for implicit and explicit (two molecules, structures denoted with *) water solvation at the PBE0-D3/def2-TZVP/SMD(water) level of theory. 
Bond dissociation energies for leaving groups in $\mathbf{5}$ :

$\mathrm{C}-\mathrm{Br} 49.0 \mathrm{kcal} / \mathrm{mol}$

C-S $52.5 \mathrm{kcal} / \mathrm{mol}$

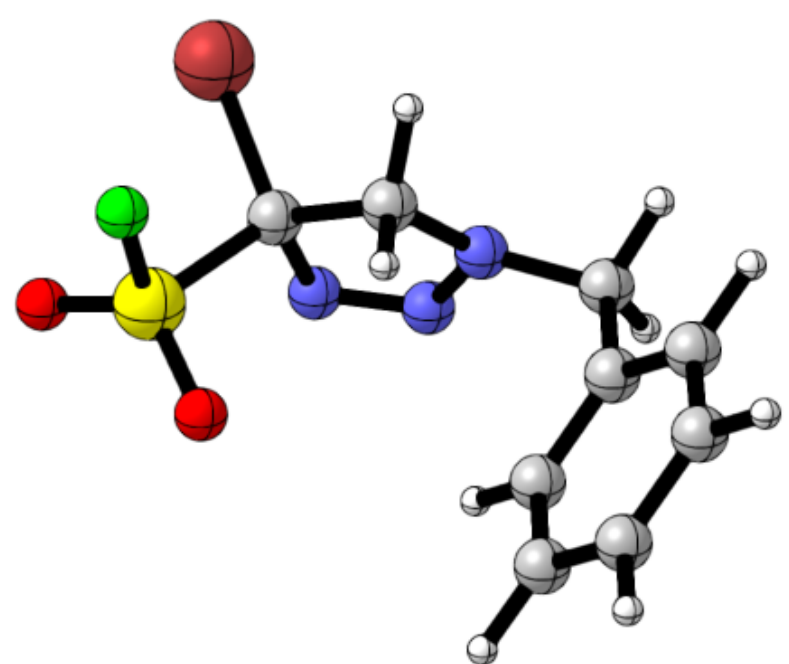

Figure S32. Molecular structure of $\mathbf{5}$ optimized at PBE0-D3/def2-TZVP/SMD(water) level of theory. 


\section{NMR spectra}

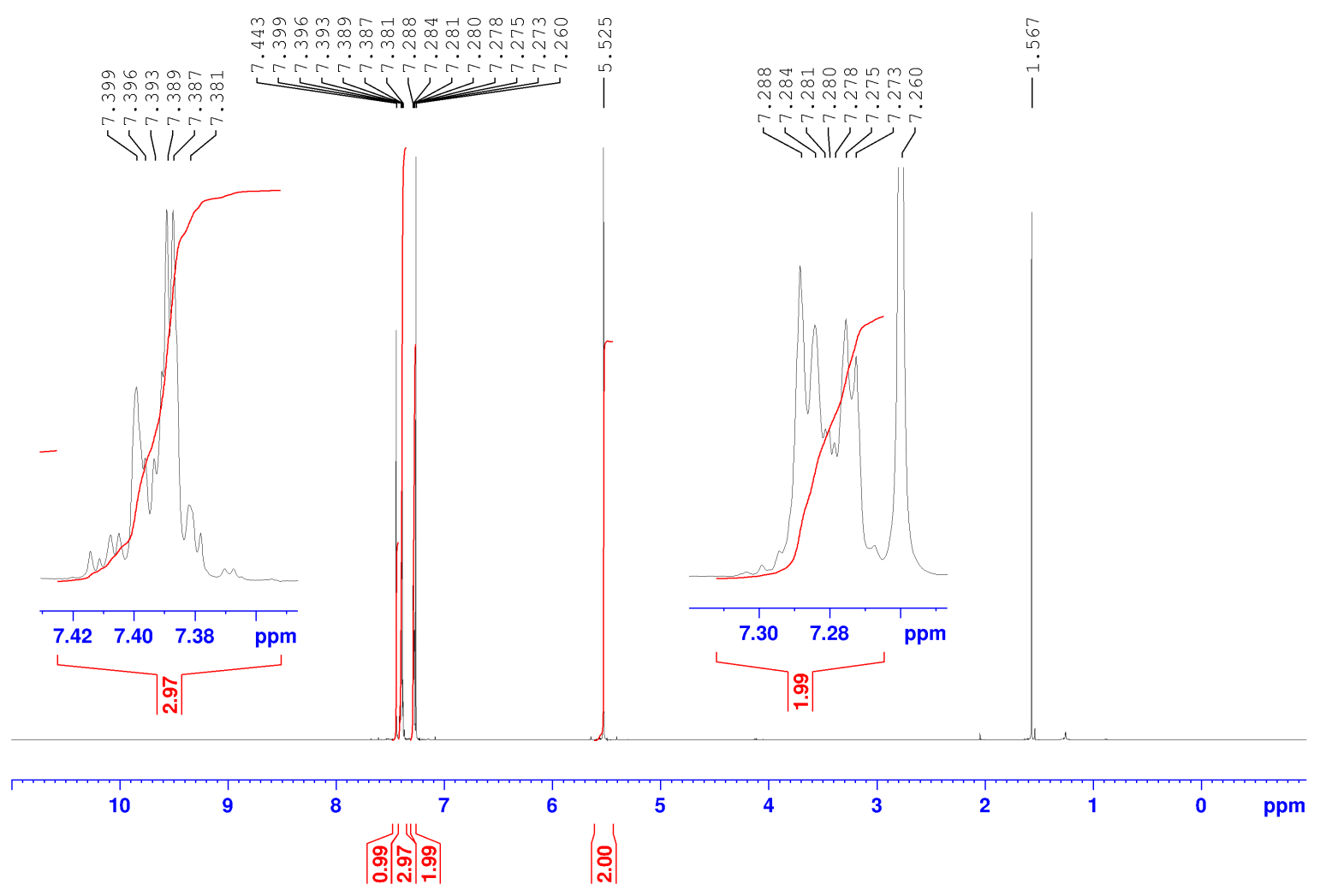

Figure S33. ${ }^{1} \mathrm{H}$ NMR spectrum of 1-benzyl-4-bromo-1,2,3-triazole (3) in $\mathrm{CDCl}_{3}$.

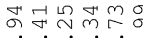

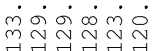

पर/1/
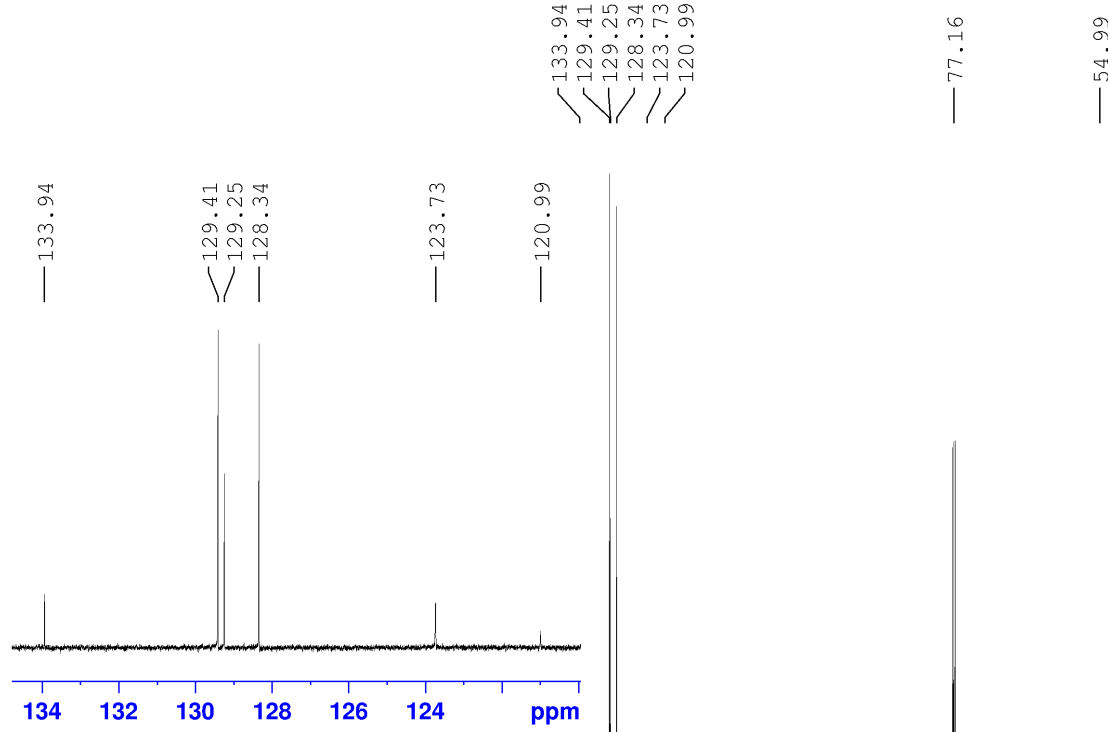

pm
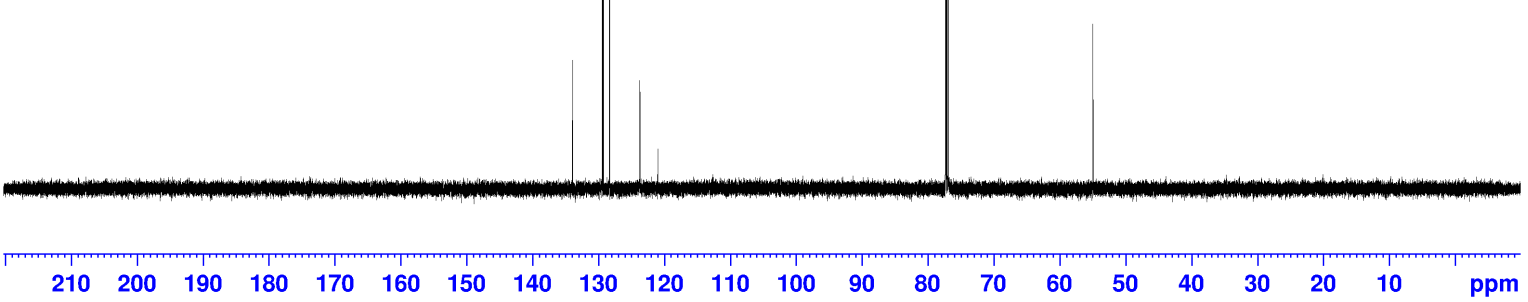

Figure S34. ${ }^{13} \mathrm{C}$ NMR spectrum of 1-benzyl-4-bromo-1,2,3-triazole (3) in $\mathrm{CDCl}_{3}$. 


\section{References}

[1] (a) J. Thomas, V. V. Fokin, Org. Lett. 2018, 20, 3749-3752; (b) S. N. Semenov, L. Belding, B. J. Cafferty, M. P. S. Mousavi, A. M. Finogenova, R. S. Cruz, E. V. Skorb, G. M. Whitesides, J. Am. Chem. Soc. 2018, 140, 10221-10232.

[2] C. Adamo, V. Barone, J. Chem. Phys. 1999, 110, 6158-6170.

[3] (a) S. Grimme, J. Antony, S. Ehrlich, H. Krieg, J. Chem. Phys. 2010, 132, 154104; (b) S. Grimme, S. Ehrlich, L. Goerigk, J. Comput. Chem. 2011, 32, 1456-1465.

[4] F. Weigend, R. Ahlrichs, Phys. Chem. Chem. Phys. 2005, 7, 3297-3305.

[5] Y. Shao, Z. Gan, E. Epifanovsky, A. T. B. Gilbert, M. Wormit, J. Kussmann, A. W. Lange, A. Behn, J. Deng, X. Feng, D. Ghosh, M. Goldey, P. R. Horn, L. D. Jacobson, I. Kaliman, R. Z. Khaliullin, T. Kuś, A. Landau, J. Liu, E. I. Proynov, Y. M. Rhee, R. M. Richard, M. A. Rohrdanz, R. P. Steele, E. J. Sundstrom, H. L. Woodcock, P. M. Zimmerman, D. Zuev, B. Albrecht, E. Alguire, B. Austin, G. J. O. Beran, Y. A. Bernard, E. Berquist, K. Brandhorst, K. B. Bravaya, S. T. Brown, D. Casanova, C.-M. Chang, Y. Chen, S. H. Chien, K. D. Closser, D. L. Crittenden, M. Diedenhofen, R. A. DiStasio, H. Do, A. D. Dutoi, R. G. Edgar, S. Fatehi, L. Fusti-Molnar, A. Ghysels, A. Golubeva-Zadorozhnaya, J. Gomes, M. W. D. Hanson-Heine, P. H. P. Harbach, A. W. Hauser, E. G. Hohenstein, Z. C. Holden, T.-C. Jagau, H. Ji, B. Kaduk, K. Khistyaev, J. Kim, J. Kim, R. A. King, P. Klunzinger, D. Kosenkov, T. Kowalczyk, C. M. Krauter, K. U. Lao, A. D. Laurent, K. V. Lawler, S. V. Levchenko, C. Y. Lin, F. Liu, E. Livshits, R. C. Lochan, A. Luenser, P. Manohar, S. F. Manzer, S.-P. Mao, N. Mardirossian, A. V. Marenich, S. A. Maurer, N. J. Mayhall, E. Neuscamman, C. M. Oana, R. Olivares-Amaya, D. P. O'Neill, J. A. Parkhill, T. M. Perrine, R. Peverati, A. Prociuk, D. R. Rehn, E. Rosta, N. J. Russ, S. M. Sharada, S. Sharma, D. W. Small, A. Sodt, et al., Mol. Phys. 2014, 113, 184-215.

[6] (a) C. Aldaz, J. A. Kammeraad, P. M. Zimmerman, Phys. Chem. Chem. Phys. 2018, 20, 2739427405; (b) L. P. Wang, C. Song, J. Chem. Phys. 2016, 144, 214108.

[7] CYLview20; Legault, C. Y., Université de Sherbrooke, 2020 (http://www.cylview.org).

[8] iQmol 2.15; Gilbert, A., 2020 (http://iqmol.org).

[9] N. M. O'Boyle, A. L. Tenderholt, K. M. Langner, J. Comput. Chem. 2008, 29, 839-845.

[10] https://github.com/giacomomarchioro/PyEnergyDiagrams. 